US Army Corps

of Engineers $s_{\circledast}$

Engineer Research and

Development Center

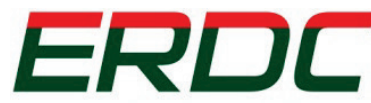

INNOVATIVE SOLUTIONS for a safer, better world

Coastal Field Data Collection Program

Collection, Processing, and Accuracy of Mobile Terrestrial Lidar Survey Data in the Coastal Environment

Nicholas J. Spore and Katherine L. Brodie

April 2017 
The U.S. Army Engineer Research and Development Center (ERDC) solves the nation's toughest engineering and environmental challenges. ERDC develops innovative solutions in civil and military engineering, geospatial sciences, water resources, and environmental sciences for the Army, the Department of Defense, civilian agencies, and our nation's public good. Find out more at www.erdc.usace.army.mil.

To search for other technical reports published by ERDC, visit the ERDC online library at http://acwc.sdp.sirsi.net/client/default. 


\section{Collection, Processing, and Accuracy of Mobile Terrestrial Lidar Survey Data in the Coastal Environment}

Nicholas J. Spore and Katherine L. Brodie

Field Research Facility

U.S. Army Engineer Research and Development Center

1261 Duck Road

Kitty Hawk, NC 27949

Final report

Approved for public release; distribution is unlimited.

Prepared for U.S. Army Corps of Engineers

Washington, DC 20314-1000

Under Work Unit H70H6B 


\section{Abstract}

The purpose of this Coastal and Hydraulics Engineering technical report is to present how elevation data is collected along the coast using terrestrial lidar scanners coupled with a global position system/inertial navigation system and assess the accuracy of the data. A brief overview of the technology utilized on the vehicle platform is presented, along with upcoming improvements. This is followed by a description of the data processing techniques utilized to create three-dimensional point clouds. Subsequent to that is a presentation of an accuracy assessment to provide an overall system performance summary and provide a few examples of data products and their uses. The accuracy assessment of the system resulted in a mean horizontal error of 0.075 meter $(\mathrm{m})$, mean vertical error of $0.099 \mathrm{~m}$, mean total error of $0.129 \mathrm{~m}$, and an average repeatability of $0.05 \mathrm{~m}$. The results of this report suggest that assigning a single accuracy value to a mobile lidar survey may misrepresent some of the spatially variable error throughout the survey, and further work should incorporate full error propagation to each point.

DISCLAIMER: The contents of this report are not to be used for advertising, publication, or promotional purposes. Citation of trade names does not constitute an official endorsement or approval of the use of such commercial products. All product names and trademarks cited are the property of their respective owners. The findings of this report are not to be construed as an official Department of the Army position unless so designated by other authorized documents. 


\section{Contents}

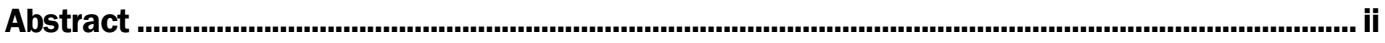

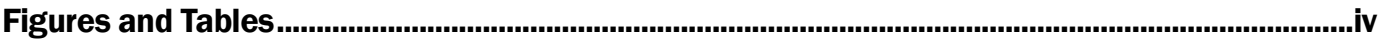

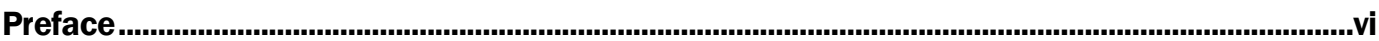

1 Introduction ................................................................................................................................. 1

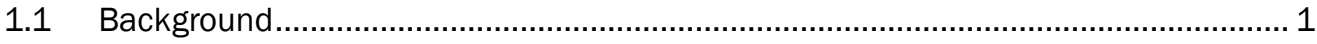

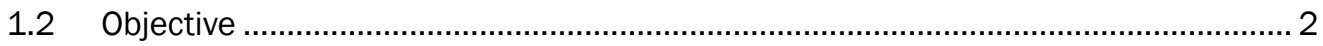

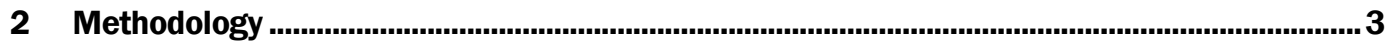

2.1 Features and specifications............................................................................... 3

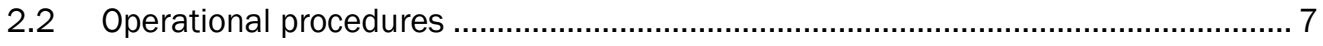

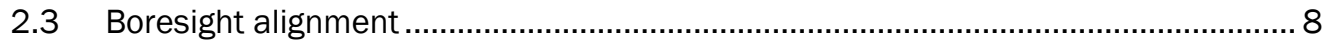

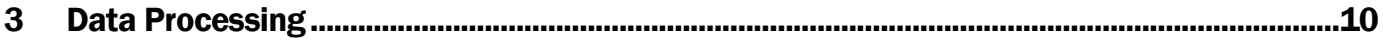

3.1 Global positioning system (GPS) ................................................................... 10

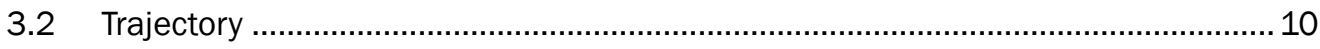

3.3 Boresight alignment ................................................................................. 11

3.4 Survey extent .......................................................................................... 14

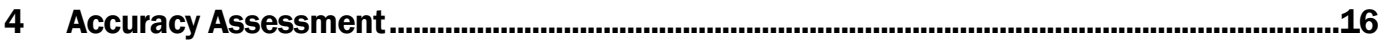

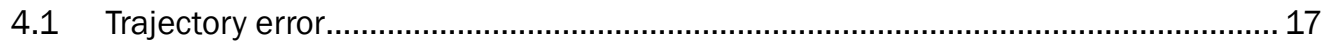

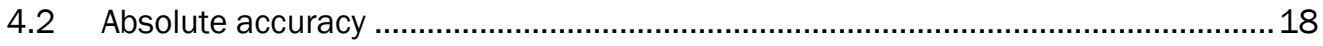

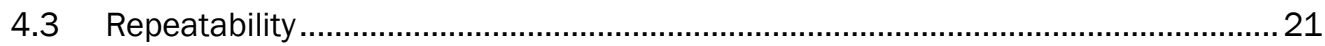

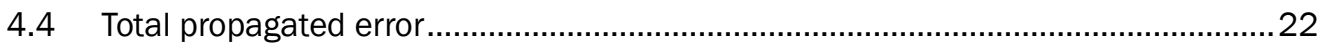

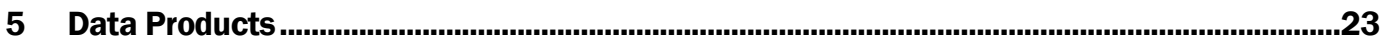

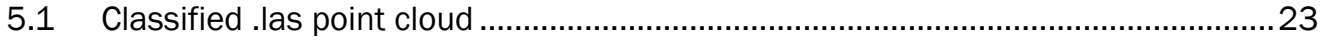

5.2 Digital elevation model (DEM) generation ......................................................... 24

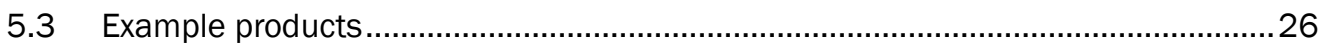

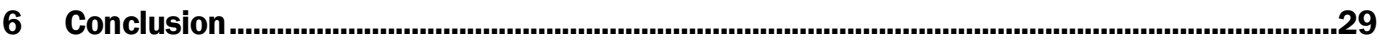

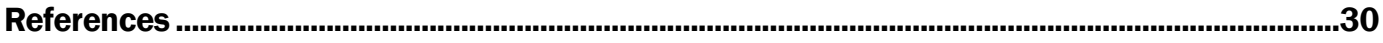

Report Documentation Page 


\section{Figures and Tables}

\section{Figures}

Figure 1. The progression of CLARIS research and development through the years 20072016, left to right: Kubota UTV, Chevrolet Blazer, Prinoth track vehicle, and Ford F350 truck.

Figure 2. Conceptual diagram of CLARIS lidar system..

Figure 3. Offshore (A) and onshore (B) data collection procedures combined creates a seamless 3D survey region.

Figure 4. The coupled lidar and IMU sensor mount used on CLARIS shown on the left. The right panel is a zoomed view of the mounting surfaces between the two sensors where the red dashed lines represent an ideal flat surface and the black lines represent the mounting surface of each sensor. $\alpha+\alpha$ ' represent the angle that must be resolved for proper point cloud rectification. This is accomplished in the boresight alignment......

Figure 5. Position (left) and orientation (right) RMS estimated errors reported throughout a typical $20 \mathrm{~km}$ survey.

Figure 6. Scans of the edge of a house colored by the different scan angles before the boresight alignment (left panel), showing point spread on a flat vertical structure of 25 $\mathrm{cm}$. After the correct angles are calculated and applied to the points, the aligned points have a point spread less than $10 \mathrm{~cm}$ for the same surface (right panel).

Figure 7. Example of least-squares plane fitting solution results; the left pane shows the distribution of residuals between the fitted planes and the right pane shows the orientation of the planes. Note that the plane orientations are well distributed around the compass, providing a more robust boresight angle solution.

Figure 8. Deviation map shown in panel A with the corresponding scale; area of scan overlap denoted by the black dashed line. Panel B shows an area of high point deviation outlined by the red rectangle $\mathrm{B}$, and panel $\mathrm{C}$ shows an area of lower point deviation outlined by the red rectangle $C$.

Figure 9. Vertical error (colors and contours) as a function of range (meters) from the scanner and estimated roll error (degrees).

Figure 10. Average horizontal error at each control point location for 10 surveys along a $20 \mathrm{~km}$ stretch of coastline.

Figure 11. Average vertical error at each control point location for 10 surveys along a 20 $\mathrm{km}$ stretch of coastline.

Figure 12. Average total error at each control point location for 10 surveys along a $20 \mathrm{~km}$ stretch of coastline.

Figure 13. The average precision of the system is $0.05 \mathrm{~m}$.

Figure 14. Points2Grid algorithm neighborhood search from opentopography.org; black dots represent lidar point data, red circles denote the bin size (i.e., search radius) for the DEM grid node; and the black crosses indicate the elevation estimate for the grid node (from OpenTopography 2016).

Figure 15. Cross-shore transects of the ground lidar points and the generated DEM surface showing good agreement (top panel) and poor agreement (bottom panel) between the original data and the final DEM.

Figure 16. Elevation change map results from subtracting two surveys that occur at different times ( $\mathrm{t} 1$ = Jan 2016; $\mathrm{t} 2$ = Apr 2016) but overlap spatially. Cool colors indicate 
areas of accretion, and warm colors indicate areas of erosion. Example transect plots from A-A' and B-B' are shown in the lower right.

Figure 17. 1 me, NAVD88 contour generation for five surveys overlaid on the most recent point cloud (May 16). Solid lines denote $1 \mathrm{~m}$ elevation contours from five surveys conducted between November 2015 and May 2016.

Figure 18. Dune state classification based on the geometry of the foredune, measured by the mobile, terrestrial scanner. Physical and calculated parameters of the foredune geometry are shown in the vertical bars on the left, and the resulting classification is shown on the right (from Brodie and Spore 2015).

\section{Tables}

Table 1. Pros and cons of the various CLARIS vehicle platforms throughout the years.

Table 2. Summary of position (easting $=x$, northing $=y$, elevation $=z$ ) and orientation RMS error over 10 surveys conducted from 2013 to 2015.

Table 3. Absolute errors of the system from 20 spatially distributed control locations over 10 separate surveys. 


\section{Preface}

This study was conducted for the U.S. Army Corps of Engineers under the Coastal Field Data Collection Program. The technical monitor was Dr. Jeffrey P. Waters.

The work was performed by the Coastal Observations and Analysis Branch (CEERD-HFA) of the Flood and Storm Protection Division (CEERD-HF), U.S. Army Engineer Research and Development Center, Coastal and Hydraulics Laboratory (ERDC-CHL). At the time of publication of this report, Dr. Jeffrey P. Waters was Chief, CEERD-HFA; Dr. Cary Talbot was Chief, CEERD-HF; Dr. Jeffrey P. Waters was Program Manager of the Coastal Field Data Collection Program; and Dr. Julie Rosati was Acting Technical Director of the Flood and Coastal Programs, Technical Programs Office. The Deputy Director of ERDC-CHL was Jeffrey R. Eckstein, and the Director was José E. Sánchez.

COL Bryan S. Green was the Commander of ERDC, and the Director was Dr. David W. Pittman. 


\section{Introduction}

\subsection{Background}

Monitoring the coastline and its surroundings necessitates frequent sampling and mapping to understand the coastal processes and provide guidance for management decisions. Obstacles include continuous tide and wave influence on the morphology as well as the stability of permanent control monuments. The challenges of mapping and monitoring the coastal terrain given the dynamic nature of the system have evolved over the years, with increased spatial and temporal sampling. Early techniques relied on repeated, cross-shore transects using a survey transit and level rod. The electronic transit integrated with a distance meter (total station theodolite) increased the number of measurements. This was followed by the development of the satellite-based global positioning system (GPS) and lidar units, capable of high point-density, three-dimensional (3D) geospatial data. Also known as laser scanning systems, lidar has since been coupled with position and orientation sensors, enabling mobile mapping systems (MMS) utilized on both aerial and terrestrial platforms (Toth 2009).

Aerial lidar surveys mounted on a helicopter or airplane achieve the greatest spatial coverage but are currently limited in point density when compared to the terrestrial counterpart due to the sampling speed. Aerial surveys are typically more costly, requiring more planning and logistics (e.g., fuel and environmentally favorable conditions). Static, tripod-mounted systems are less expensive and output more detailed maps but are limited in spatial coverage. Mobile terrestrial systems offer a balance between the two aforementioned techniques and are able to provide high-resolution data at lower operational costs while rapidly deployable (Barber and Mills 2007). The use and accuracy of mobile terrestrial systems has been well documented in urban (Haala et al. 2008; Barber et al. 2008) and coastal environments (Barber and Mills 2007; Bitenc et al. 2011; Lim et al. 2013). It serves well to complement airborne lidar surveys by resolving more detailed structure such as building sides or foredune faces with the denser point spacing and oblique scanning angles.

Mobile, terrestrial-based lidar systems offer the benefits of traditional, stationary high-resolution scanning and given a high-precision navigation 
system, allow for large regional surveys to be conducted within hours at comparable resolution. The Coastal and Hydraulics Laboratory, Field Research Facility (FRF), utilizes this technology to monitor beach elevation throughout the year on seasonal scale as well as before, during, and after extratropical, subtropical, and tropical storms or hurricanes. The observational data are critical for understanding spatial and temporal trends of beach morphological evolution within the time scale of a storm event, seasons, years, and ultimately decades. The data can also be used to improve model predictions of coastal inundation and vulnerability during storms, quantify during-storm morphodynamics, monitor beach nourishment projects, and assess large-scale sediment transport and morphology evolution.

\subsection{Objective}

This report presents the FRF's current mobile terrestrial lidar surveying system. Chapter 2 focuses on the system components and concept of operation required for data acquisition. Chapter 3 details how the data are processed. Quality and accuracy assessments, error sources, absolute error, and repeatability of the system are addressed in Chapter 4. The resulting data products are presented in Chapter 5 followed by concluding statements in Chapter 6. 


\section{Methodology}

This chapter describes the hardware components and operational procedure for conducting a terrestrial lidar survey of the subaerial beach and foredune face. The components of the current system are introduced including the vehicle base and sensors. This is followed by the standard operating procedures used to acquire the survey data along with methods used to properly align the sensors.

\subsection{Features and specifications}

Collecting quality data while driving on soft and partially saturated sand during storm conditions has led to a progression of vehicular platforms (Figure 1), with each one intending to improve on the previous. The FRF's Coastal Lidar and Radar Imaging System (CLARIS) is currently mounted on a stand-alone, weather-proof box on the back of a four-wheel drive (4WD), highway-operable truck. The active sensors that collect the data are mounted on the top of the custom-fabricated rear compartment, and the rest of the hardware is housed within the compartment or within the passenger cabin. The system is operated by two people-the driver and the surveyor, with the latter in charge of data collection. A future version of the system will be mounted on a 4WD van to enable better environmental protection for the equipment and easy access to data collection systems by the passenger during collection. A series of pros and cons for each vehicle (past through future) are listed in Table 1 for each vehicle tested in the progression.

Figure 1. The progression of CLARIS research and development through the years 20072016, left to right: Kubota UTV, Chevrolet Blazer, Prinoth track vehicle, and Ford F350 truck.

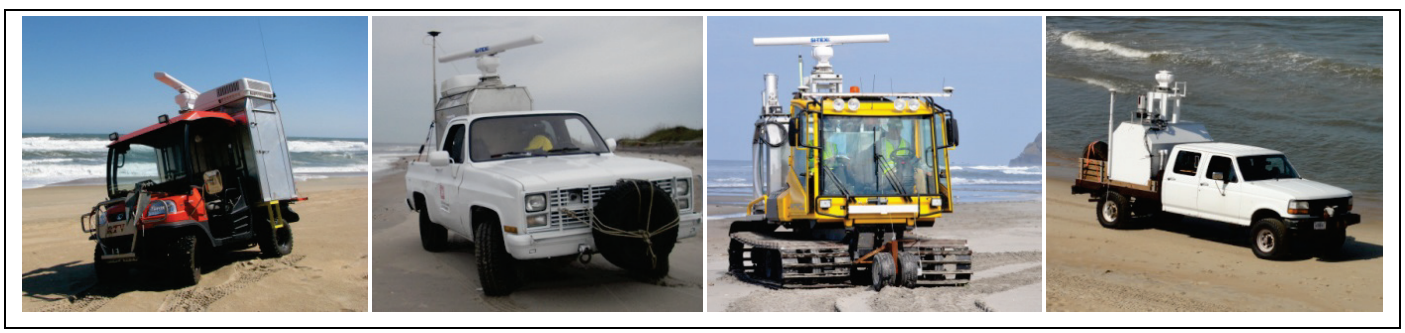


Table 1. Pros and cons of the various CLARIS vehicle platforms throughout the years.

\begin{tabular}{|l|l|l|}
\hline Vehicle Platform & Pros & Cons \\
\hline $\begin{array}{l}\text { Kubota UTV } \\
\text { (2007-2008) }\end{array}$ & $\begin{array}{l}\text { Short wheel base } \\
\text { Lightweight }\end{array}$ & $\begin{array}{l}\text { Small ground clearance } \\
\text { Prone to getting stuck in soft } \\
\text { sand } \\
\text { Lack of climate control } \\
\text { Not highway operable }\end{array}$ \\
\hline $\begin{array}{l}\text { Chevrolet Blazer } \\
\text { (2008-2010) }\end{array}$ & $\begin{array}{l}\text { Short wheel base } \\
\text { Good low-end torque } \\
\text { Powerful motor } \\
\text { Highway capable }\end{array}$ & $\begin{array}{l}\text { Vehicle age affected integrity } \\
\text { Lack of climate control }\end{array}$ \\
\hline $\begin{array}{l}\text { Prinoth Track Vehicle } \\
\text { (2010-2012) }\end{array}$ & $\begin{array}{l}\text { Surveyor position located } \\
\text { within passenger cabin } \\
\text { Climate controlled }\end{array}$ & $\begin{array}{l}\text { Track integrity weak while } \\
\text { driving on sand-prone to } \\
\text { breakage } \\
\text { Not highway operable } \\
\text { Heavy vibrations }\end{array}$ \\
\hline $\begin{array}{l}\text { Ford F350 Truck } \\
\text { (2012-present) }\end{array}$ & $\begin{array}{l}\text { Good low-end torque } \\
\text { Powerful motor } \\
\text { Large monitor array for } \\
\text { surveyor to assess acquisition } \\
\text { quality } \\
\text { Highway capable }\end{array}$ & $\begin{array}{l}\text { Leavy curb weight } \\
\text { Vehicle age affected integrity }\end{array}$ \\
\hline $\begin{array}{l}\text { Chevrolet 3500 } \\
\text { (future) }\end{array}$ & $\begin{array}{l}\text { All equipment within } \\
\text { passenger cabin } \\
\text { Climate controlled } \\
\text { Short wheelbase } \\
\text { Upgraded system components }\end{array}$ & $\begin{array}{l}\text { Slightly top heavy } \\
\text { Cost }\end{array}$ \\
\hline
\end{tabular}

The following sensors, computer hardware, and software are integrated on-board CLARIS:

- Riegl VZ-100o Lidar Scanner; class 1 laser (Riegl 2015)

\begin{tabular}{|l|l|}
\hline Laser wavelength & $1550 \mathrm{~nm}$ (near infrared) \\
\hline Range & $2.5-1400$ meters $(\mathrm{m})$ \\
\hline Horizontal angular stepwidth resolution & $0.0024-0.5$ degrees $(\mathrm{deg})$ \\
\hline Vertical angular stepwidth resolution & $0.0024-0.288 \mathrm{deg}$ \\
\hline Accuracy & 8 millimeters $(\mathrm{mm})$ \\
\hline Precision & $5 \mathrm{~mm}$ \\
\hline
\end{tabular}

- Applanix POS-LV 220 Inertial Navigation System (INS) with integrated inertial measurement unit (IMU), distance measurement instrument (DMI), and two global navigation satellite system antennas. The published accuracy of the system, as stated by the manufacturer, is shown in the following (Applanix 2015): 


\begin{tabular}{|l|l|}
\hline Minimum Root Mean Square (RMS) Error (Post-Processed Solution) \\
\hline Horizontal (X,Y) position & $0.020 \mathrm{~m}$ \\
\hline Vertical (Z) position (m) & $0.050 \mathrm{~m}$ \\
\hline Roll and pitch (deg) & $0.020 \mathrm{deg}$ \\
\hline True heading (deg) & $0.025 \mathrm{deg}$ \\
\hline
\end{tabular}

- SiTek 4kW X-Band Radar with 2 deg beam width capable of at least 1 kilometer $(\mathrm{km})$ range

- Three mobile acquisition computer systems with solid-state hard drives

- Riegl RiAcquire software for acquiring and displaying data flow in real time

- Applanix POSView software for controlling and analyzing the INS trajectory metrics

- Custom-designed, analog-to-digital conversion card for processing radar intensity data

The new system will continue to build off of the previous variants but will incorporate improvements to accuracy, data flow, resiliency, and rapid response of the system. This includes the following:

- Riegl VZ-200o lidar scanner; faster and more powerful laser operating at 1550 nanometers $(\mathrm{nm})$ wavelength capable of mobile framescans (Riegl 2015)

\begin{tabular}{|l|l|}
\hline Laser wavelength & $1550 \mathrm{~nm}$ (near infrared) \\
\hline Range & $2.5-2050 \mathrm{~m}$ \\
\hline Horizontal angular stepwidth resolution & $0.0024-0.62 \mathrm{deg}$ \\
\hline Vertical angular stepwidth resolution & $0.0015-1.15 \mathrm{deg}$ \\
\hline Accuracy & $8 \mathrm{~mm}$ \\
\hline Precision & $5 \mathrm{~mm}$ \\
\hline
\end{tabular}

- IX-Blue ATLANS-C navigation system (IXBlue 2016)

\begin{tabular}{|l|l|}
\hline \multicolumn{2}{|l|}{ Minimum RMS Error (Post-Processed Solution) } \\
\hline Horizontal (X,Y) position & $0.020 \mathrm{~m}$ \\
\hline Vertical (Z) position (m) & $0.050 \mathrm{~m}$ \\
\hline Roll and pitch (deg) & $0.005 \mathrm{deg}$ \\
\hline True heading (deg) & $0.020 \mathrm{deg}$ \\
\hline
\end{tabular}

- LadyBug 3 spherical camera capable of capturing mobile panoramic images to colorize the final point cloud with its respective RGB values for additional environmental analysis 
- Furuno 6kW X-band Radar with software development kit included for improved scripting control over the sensor and its data stream with the ability to analyze data coverage on-the-fly

- Improved synchronization between all sensors for accurate trajectory application to all data types

- Stainless steel, all-in-one solid-state computer/touchscreen monitors alleviate the need for bulky protective housings

A conceptual diagram describing the integration of the individual sensor components is presented in Figure 2. Position, orientation, and velocity data from the GPS antennas, IMU, and DMI are compiled within a central INS coupler (green boxes). The INS coupler also synchronizes the trajectory data with the timing of the lidar scanner (red box). The INS coupler sends a timing pulse per second to ensure the two sensors maintain synchronous time without drift and that each lidar point is properly time stamped. The lidar and trajectory data are then combined in post-processing to rectify each data point in space. All of the data coming from the scanner and the INS system are stored on a central acquisition computer that is accessible by the operator in the field and updates in real time.

Figure 2. Conceptual diagram of CLARIS lidar system.

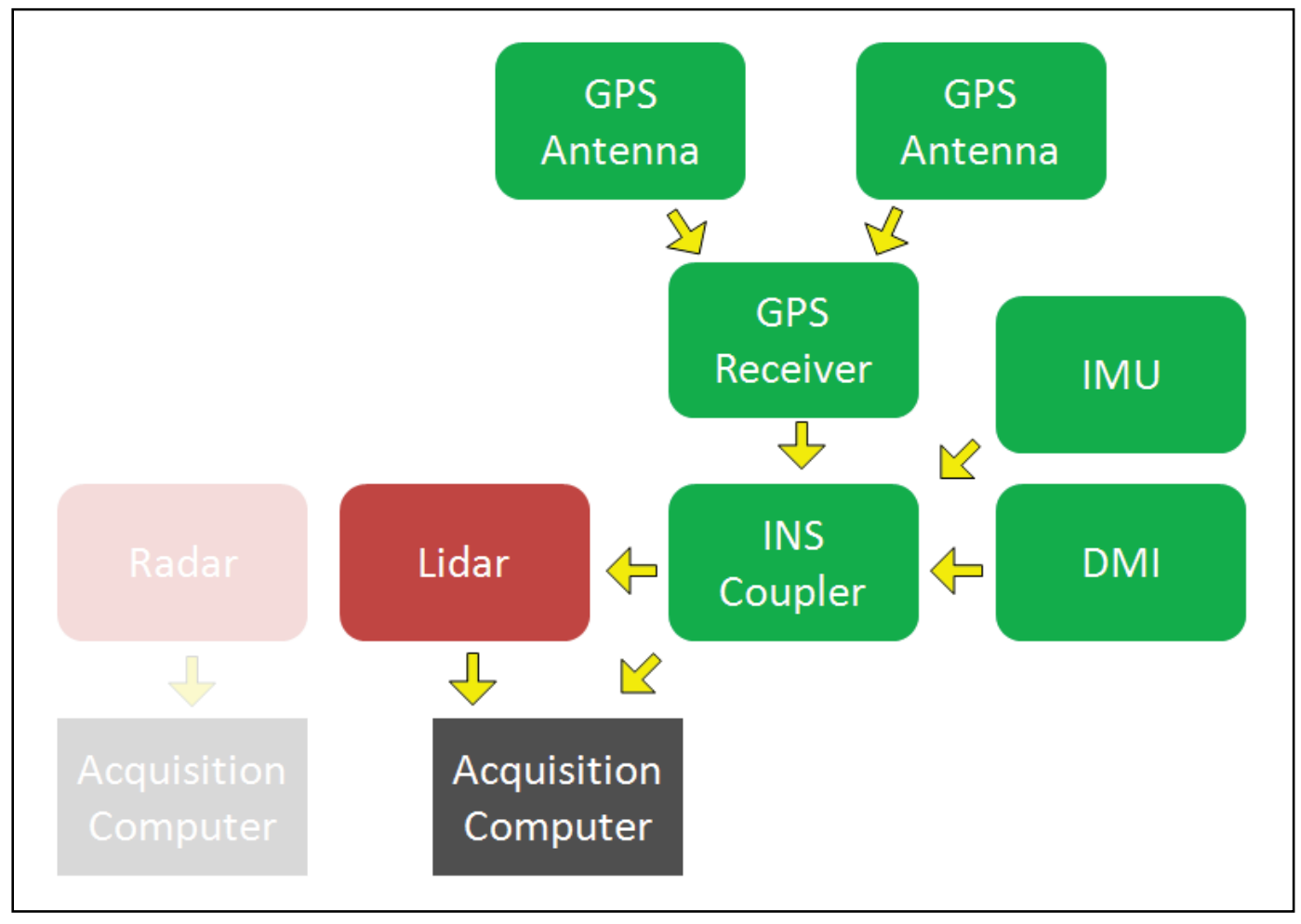




\subsection{Operational procedures}

A typical mobile survey begins with initialization of the GPS/INS system to acquire stable position, attitude, and velocity data through a series of automated leveling and satellite locking routines. Once there is a signal lock on at least seven GPS satellites and the GPS Azimuth Measurement Subsystem calculates a fixed solution for the two GPS antennas' separation, the calibration procedure for GPS/INS system can begin. The vehicle operator drives around a calibration site where figure-eight turns and sudden accelerations and decelerations are used to move and level the sensitive gyroscopes contained within the IMU. Once the attitude (roll, pitch, and yaw) accuracy values reach the desired minimum threshold based on the instrument's precision (0.02 deg for the POS-LV 220 system), the navigation system is sufficiently calibrated to begin field data collection.

Lidar data are collected at a peak pulse repetition rate of 300 kilohertz $(\mathrm{kHz})$. This results in 122,000 measurements per second with an angular resolution of $0.08 \mathrm{deg}$ in the vertical along a narrow transect at 90 deg to the vehicle. As the survey progresses, the surrounding topography is scanned and a $3 \mathrm{D}$ point cloud is built from sequential two-dimensional linescans. A typical survey will start with the vehicle positioned parallel to the dune near the dune toe with the scanner pointed orthogonally off the passenger side and scanning offshore (Figure 3, A). The radar system is also operated while lidar scanning. The concept of operations (CONOPS) for the radar system and the accompanying data will be covered in a separate report.

After the offshore-looking scan is completed for the entire survey region, the vehicle turns around and drives parallel and near to the shoreline with the scanner pointed orthogonally off the passenger side and scanning landward toward the dune (Figure 3, B). This CONOPS allows for an overlapping region in the mid-beach, which can be used during the quality assurance/quality control (QA/QC) step to analyze the effect of errors in the vehicle trajectory during post-processing. The seaward and landward scans form a seamless point cloud of elevation data with a typical point density of 75-100 points per square meter. Current operation requires beach conditions to be safely passable and precipitation to be no more than a light rain. 
Figure 3. Offshore (A) and onshore (B) data collection procedures combined creates a seamless $3 \mathrm{D}$ survey region.

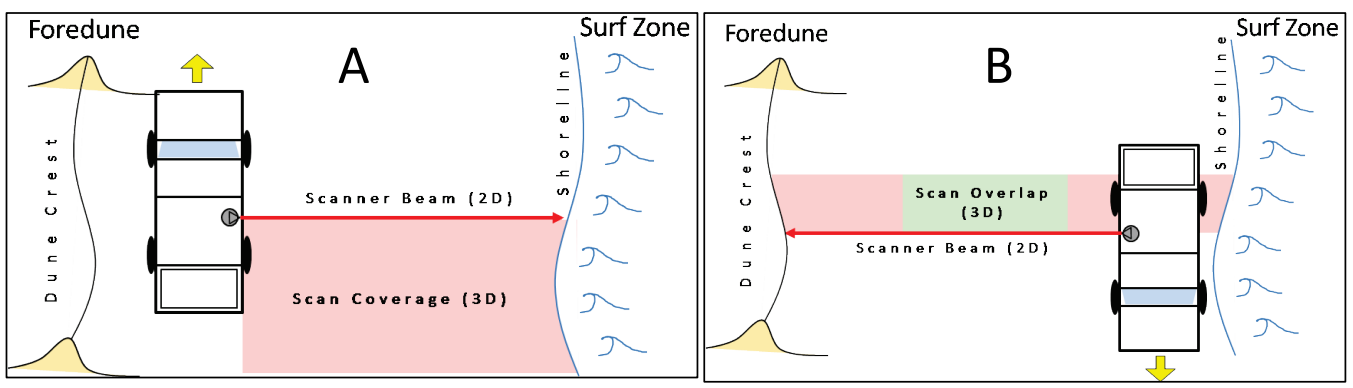

\subsection{Boresight alignment}

To collect geospatially accurate data, the alignment between the GPS/INS system and the terrestrial lidar scanner must be precisely known, as very small angular offsets between the GPS/INS system and the lidar scanner can lead to significant errors at range from the system. This process is called a boresight alignment.

The mount that couples the scanner and IMU assumes a parallel-plane plate and requires only a vertical offset between the scanner and IMU measurement centers (Figure 4). In reality, no material or mounting system is perfectly machined or aligned. These imperfections will introduce error if not properly considered/determined. Thermal expansion and contraction of the mounting surfaces or the torque applied when remounting the scanner after maintenance can cause these angular differences in mounting repeatability. Figure 4 illustrates how subtle imperfections between the mounting surfaces can introduce angular errors. 
Figure 4. The coupled lidar and IMU sensor mount used on CLARIS shown on the left. The right panel is a zoomed view of the mounting surfaces between the two sensors where the red dashed lines represent an ideal flat surface and the black lines represent the mounting surface of each sensor. $\alpha+\alpha^{\prime}$ represent the angle that must be resolved for proper point cloud rectification. This is accomplished in the boresight alignment.

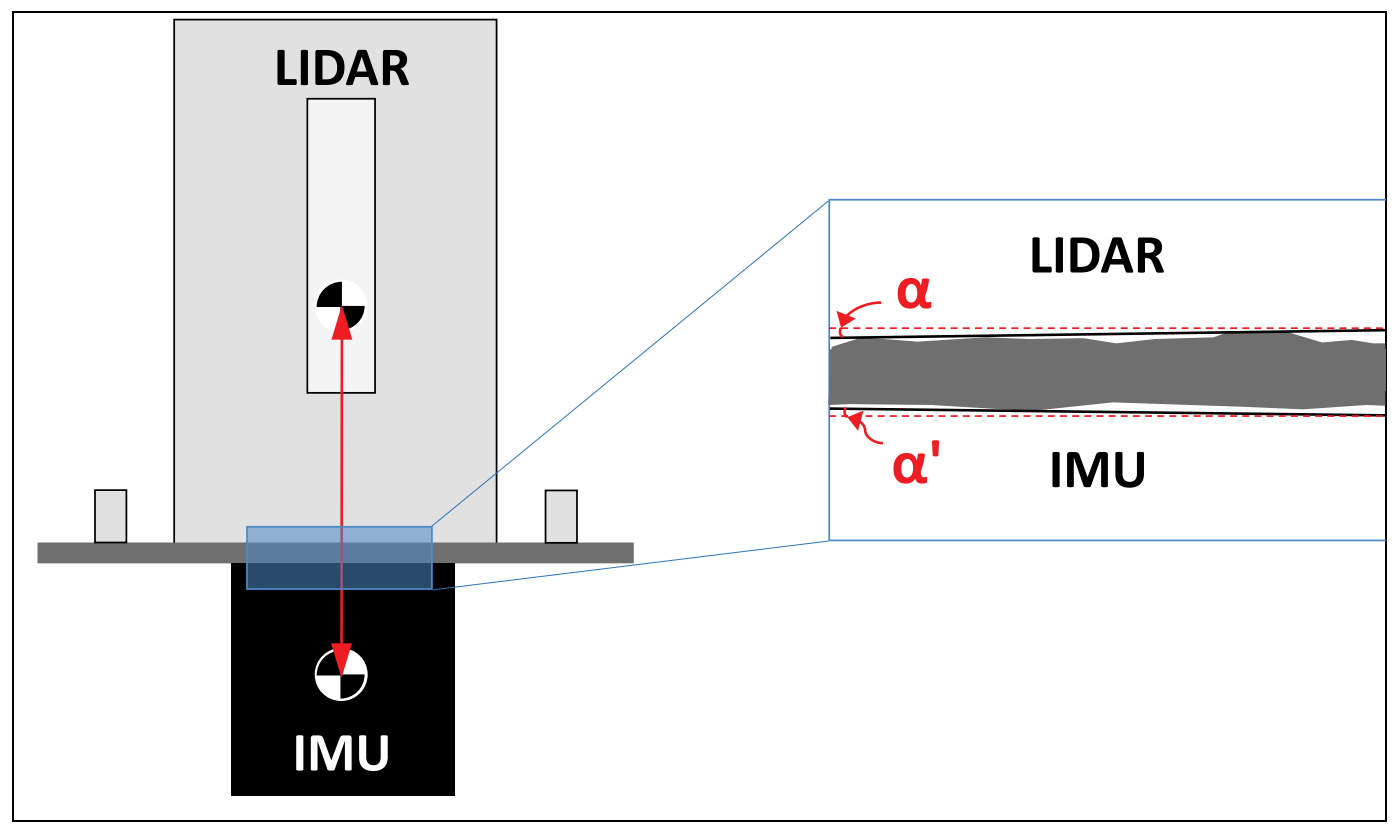

To solve for these differences, a separate calibration survey is conducted in an area that includes numerable planar surfaces with multiple orientation aspects (i.e., housing developments varying housing orientations and roof types/directions as suggested by Rieger et al. 2010). Five separate scans of the area with varying planar surfaces are performed at five different scan angles relative to the reference frame of the vehicle. These planar surfaces are used in post-processing to determine the angular offsets needed to properly align objects within the point cloud from scan to scan. This calibration survey is critical to solving for angular offsets during mounting between the laser scanner and the IMU. The processing of these data to determine the boresight calibration parameters are described in Chapter 3. 


\section{Data Processing}

Significant processing is required following the survey to generate geo-rectified point-clouds of the subaerial beach. Raw data from the scanner must be converted from polar coordinates centered on the scanner to georectified Cartesian coordinates using the information on the scanner's trajectory (orientation and position) at the time each data point was collected from the GPS/INS system. The following sections address the processing of the GPS corrections, the vehicle trajectory output by the INS, the boresight alignment, and the creation of the final point cloud.

\subsection{Global positioning system (GPS)}

The position data collected throughout the survey is logged as the raw L1/L2 signal and is post-processed to achieve centimeter accuracy. This method provides higher accuracy position information compared with a real-time kinematic (RTK) solution as it relies on the actual satellite paths when applying corrections. Depending upon the survey length, GPS data are postprocessed using data from a single Continually Operating Reference Station (CORS) (or locally set base station) in the middle of the survey site or from a network of CORS bases that encompass the survey area.

\subsection{Trajectory}

To generate trajectory data, the post-processed GPS position data are combined with the orientation data recorded by the IMU and the speed data recorded by the DMI using Applanix POSpac MMS software. Data and associated errors from each sensor are integrated within Applanix's proprietary Kalman filter to minimize errors. The Kalman filter implements a set of differential equations to model the motion of the vehicle and the component errors of the trajectory file in both the forward and backward direction. This integrated solution improves the quality of the trajectory by utilizing information from multiple sensors in the event of degraded observations from one particular component. This is particularly valuable for overcoming errors associated with GPS signal blockage, GPS multipathing, and poor GPS satellite configurations. A final smoothed, best estimate of trajectory (SBET) is output from the mean of the forward and backward processed positions. The Kalman filter also estimates smoothed trajectory performance metrics and estimated root mean square error (RMSE) for each component sensor observation as well as final errors in the trajectory orientation and position estimates. 
Example estimated RMSE for position (left panel) and orientation (right panel) for the SBET from a $20 \mathrm{~km}$ mobile survey of the beach near Duck, NC, are shown in Figure 5. The plots in Figure 3 are useful for understanding how the estimated accuracy of the trajectory improves or degrades within specific intervals of the survey. Errors are often non-static over the course of the survey and may be related to sensor drift or variations in GPS quality. Periods where estimated accuracy values are greater than 4 centimeters $(\mathrm{cm})$ RMSE for position and 0.05 deg RMSE for attitude will lead to poor rectification of lidar data and are flagged accordingly. For example, a roll error of $0.05 \mathrm{deg}$ will lead to a vertical offset of $0.1 \mathrm{~m}$ at $125 \mathrm{~m}$ range in the lidar data. An analysis of estimated errors from ten surveys is presented in Chapter 4.

Figure 5. Position (left) and orientation (right) RMS estimated errors reported throughout a typical $20 \mathrm{~km}$ survey.

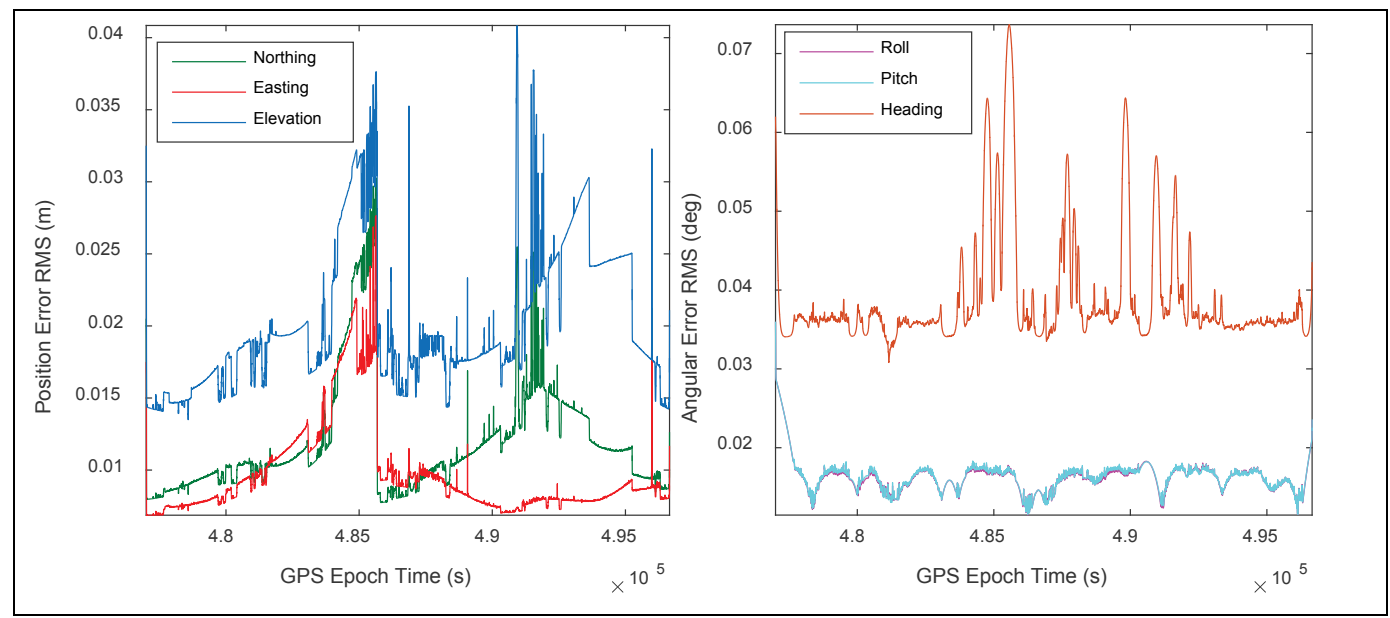

\subsection{Boresight alignment}

Once the SBET has been generated, the boresight alignment between the scanner and IMU can be calculated (France and Butler 2012). Each respective scan angle (45, 60, 90, 120, and 135 deg going clockwise from the vehicle reference frame with the front being o deg) is uncompressed from its binary .rxp format and then rectified into geographic coordinates dictated by the coordinate system of the trajectory. Initially, no offset is assumed between the scanner's orientation and the IMU (an identity rotation matrix is used to relate the scanner and the IMU). Once each scan angle is processed, all the resulting point clouds are simultaneously visualized in a cross-section view with unique colors for each angle to measure the relative offset distance between fixed structures (such as building walls, rooflines, road centerlines, etc.) for the different angled 
scans (Figure 6, left). This provides the user with initial thresholds for input parameters to the boresight alignment algorithm.

A plane-matching algorithm within Riegl's RiProcess software is used to identify the alignment needed to minimize these offsets and collapse all scan angles into a uniform point cloud with horizontal and vertical precision within the system's specifications. First, tie planes are generated to fit planar surfaces in each scan angle's point cloud. A group of points is defined as a plane when they meet a minimum plane inclination angle from ground, a maximum plane point deviation, and a minimum number of points to define the plane. A normal vector is assigned to each generated plane. Then, from scan angle to scan angle, these planes are matched given a $3 \mathrm{D}$ search radius of between plane centers, angular tolerance, and maximum normal distance between planes. In order to minimize bias, the user ensures there are several thousand plane matches that are oriented over the full 360 deg (i.e., the generated planes' aspect when plotted on a polar scale will yield a "well-balanced" compass [Figure 7, right panel]). The plane-matching algorithm solves for the roll, pitch, and yaw offset needed to bring the planes from each scan angle into alignment with each other. This routine utilizes a least squares fitting algorithm with a user-specified solution tolerance. The algorithm solves for the three free parameters (roll, pitch, yaw), and a standard deviation (error) for the matched-plane observations is reported. If the algorithm is mismatching planes between subsequent scans, these planes will have a high standard deviation, and the user removes these planes from the calculation and re-runs the algorithm. The process becomes iterative at this point, where the user will remove outlier plane matches that have high deviation between the two planes and re-run the solving routine until the reported standard deviation through all of the observations is sufficiently low (typically less than $2 \mathrm{~cm}$ [Figure 7, left panel]). 
Figure 6. Scans of the edge of a house colored by the different scan angles before the boresight alignment (left panel), showing point spread on a flat vertical structure of $25 \mathrm{~cm}$. After the correct angles are calculated and applied to the points, the aligned points have a point spread less than $10 \mathrm{~cm}$ for the same surface (right panel).
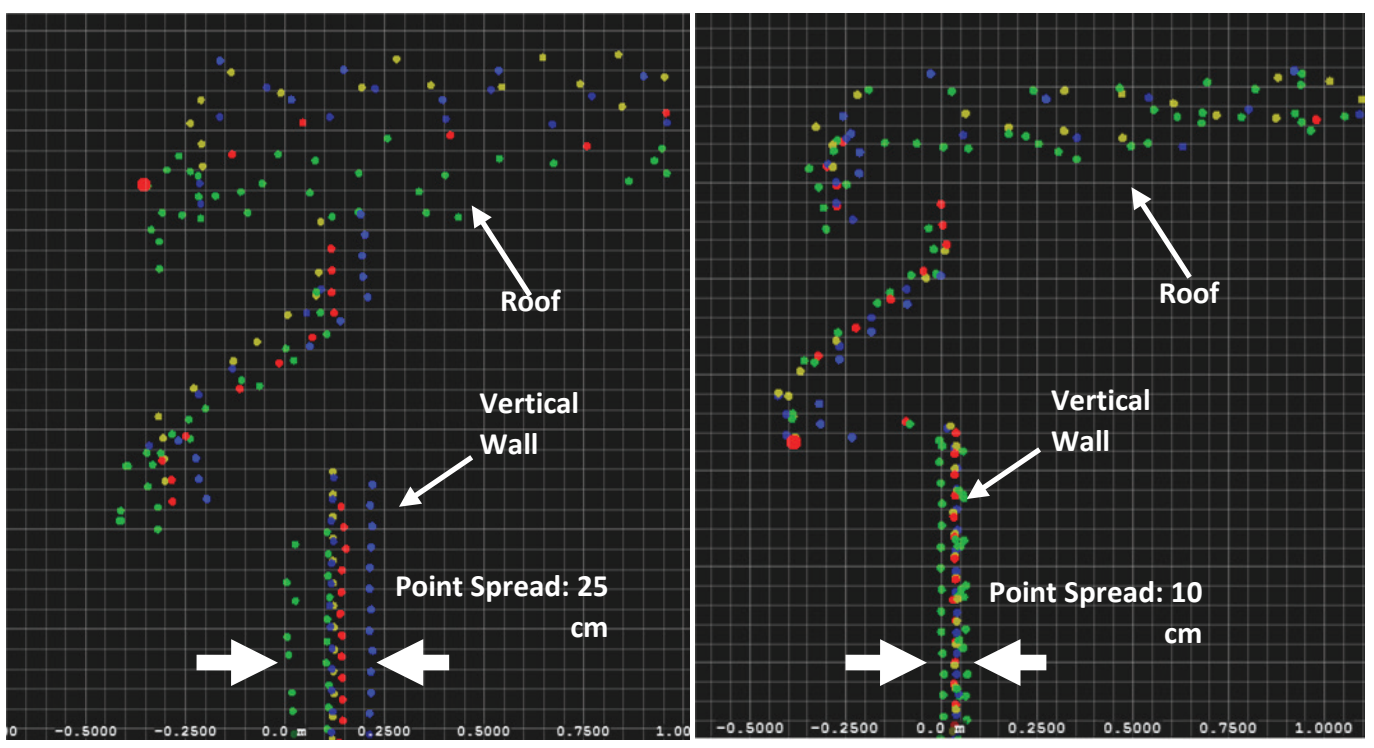

Once a solution for the roll, pitch, and yaw parameters is solved, these values are input into the scanner orientation matrix, and each scan is reprocessed and re-rectified. The user again simultaneously visualizes each angle's point cloud as a unique color similar to the initial cross-section analysis and checks that the fixed structures are now in alignment with the new orientation applied. An acceptable point deviation of a solid object should be no greater than 2-5 cm (Figure 6, right panel). Multiple cross sections are viewed throughout the boresight scan area to ensure that the corrected orientation applies for various ranges, aspects, and inclination angles. The calculated roll, pitch, and yaw values are exported and incorporated into the scanner orientation matrix and used for processing the full-extent survey.

Figure 7. Example of least-squares plane fitting solution results; the left pane shows the distribution of residuals between the fitted planes and the right pane shows the orientation of the planes. Note that the plane orientations are well distributed around the compass, providing a more robust boresight angle solution.
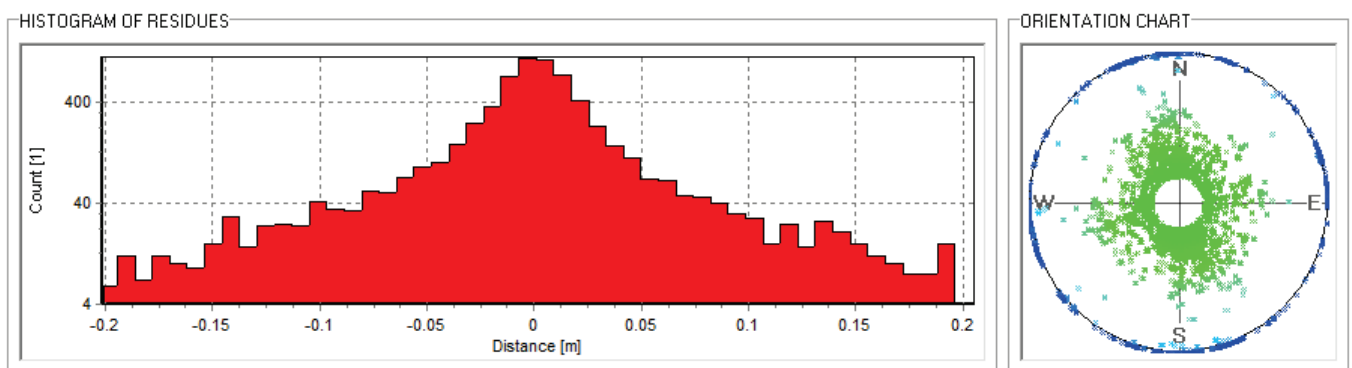


\subsection{Survey extent}

The remaining data files for the full-extent survey are then decompressed and rectified in RiProcess utilizing the scanner orientation parameters generated from the boresight alignment project and the trajectory file. Once processing is complete, the user visualizes the data in plan view colored by point-to-point vertical deviation as seen in Figure 8, A, where deviation is the vertical range in point distribution over an otherwise static target. Rectification errors (likely from errors in the GPS component of the trajectory file) can be identified as areas of high deviation in overlapping swaths of data from the northerly and southerly passes. Figure 8, A, shows in plan view a $250 \mathrm{~m}$ alongshore section of a typical coastal survey. The colors represent the vertical point deviation ranging from o (blue) to $0.1 \mathrm{~m}$ (red with white regions exceeding $0.1 \mathrm{~m}$ ), and the area of overlap between overlapping scans is represented between the two dashed black lines. The red rectangle B denotes an area where there is high deviation $(\sim 0.1 \mathrm{~m}$ deviation between passes), and a representative shore-perpendicular profile is shown in Figure 8, B. Similarly, an area of low deviation ( $\sim 0.02 \mathrm{~m}$ deviation between passes) is denoted by the red rectangle, C, in Figure 8, A, and a representative shore-perpendicular profile is shown in Figure 8, C. The deviation map also works well to assess the scanner orientation values calculated from the boresight alignment. Seamless overlap with minimal vertical deviation indicates well-aligned and properly boresighted sensors. Clear breaks or discontinuities in the overlapping regions suggest that the boresight angles are not accurate enough and must be recalculated. 
Figure 8. Deviation map shown in panel A with the corresponding scale; area of scan overlap denoted by the black dashed line. Panel $B$ shows an area of high point deviation outlined by the red rectangle $B$, and panel $C$ shows an area of lower point deviation outlined by the red rectangle $C$.
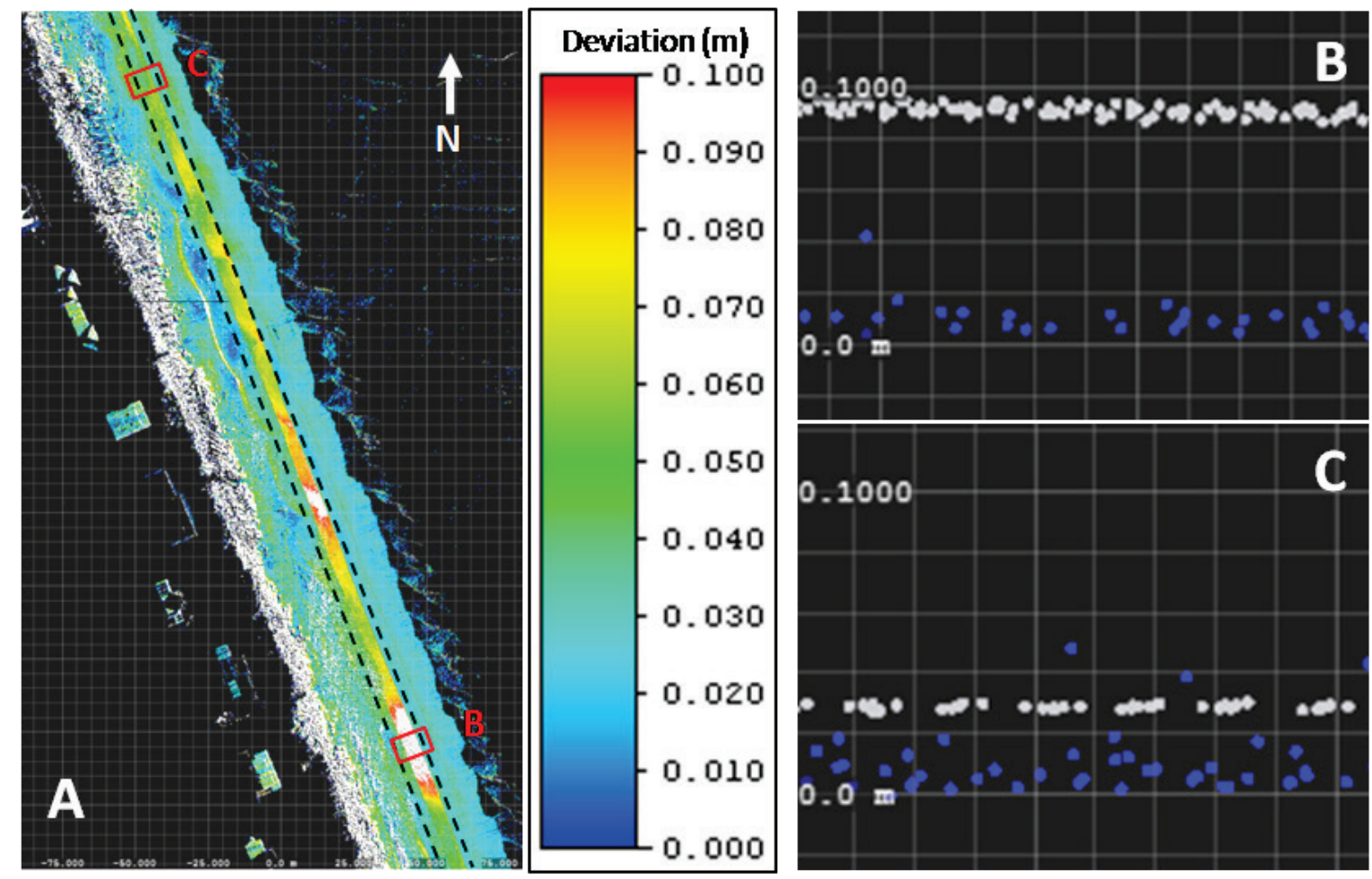


\section{Accuracy Assessment}

Sources of error in the $x, y$, and $z$ ground coordinates of rectified point clouds derived from mobile terrestrial lidar scanning include trajectory errors (including IMU attitude errors and positioning errors), boresight errors, lever-arm offset errors, and laser scanner errors. Glennie (2007) provides an excellent overview of the sources of error in terrestrial lidar point clouds and is summarized briefly here.

In the final point cloud, errors in rectification derived from IMU attitude errors (roll, pitch, yaw) are directly proportional to distance from the scanner, as small angular offsets lead to increases in position offsets that scale with range. These errors may vary with instrument drift throughout the course of the survey. Errors in rectification due to positioning errors in the trajectory derive from the quality of GPS during the survey and are affected by atmospheric conditions, GPS multipathing, satellite configuration, and distance from the base station. Glennie (2007) notes that GPS position errors at baselines of $<30 \mathrm{~km}$ from the base station, with no drop-outs, good satellite geometry, and negligible multipathing, should be on the order of $+/-2 \mathrm{~cm}$ horizontally and vertically. The effect of these errors is a simple vertical or horizontal translation of the coordinates in space; however, the magnitude of these errors may vary during the survey depending upon the aforementioned factors affecting GPS quality. Errors deriving from boresight alignment are generally low $(<0.001$ degrees in roll and pitch; <0.004 deg in yaw) after the boresight calibration is performed. Inaccurate boresight alignment will have a similar effect to IMU attitude errors but will be remain constant for the entire survey. Glennie (2007) reduces his discussion of errors derived from the laser scanner to errors in measuring distance and angle. Errors in distance derive from errors in the timing of the scanner's internal clock whereas errors in angle derive from the resolution of the scanner's angular encoder and the scanner's beam divergence, with the latter also being a function of the incidence angle relative to the terrain's slope.

In this chapter, there is an assessment of errors in the trajectory (including attitude and GPS error) using ten mobile lidar surveys of the beach near Duck, NC. Then there is an assessment of the absolute accuracy of the mobile lidar system through a comparison to control points along the survey area, as well as the repeatability of the surveys using hard, fixed 
structures. The analysis focuses on identifying any spatial variability in our errors along the study-site.

\subsection{Trajectory error}

Independently estimating errors in trajectory is difficult without adding additional sensors to the vehicle. Glennie (2007) suggests using the manufacturer specifications as a starting point for estimating potential errors in the trajectory. The manufacturer specifications for errors in the trajectory from the GNSS given good GPS are $0.02 \mathrm{~m}$ horizontal, $0.05 \mathrm{~m}$ vertical, $0.020 \mathrm{deg}$ in roll/pitch, and $0.025 \mathrm{deg}$ in true heading. To demonstrate the relationship between errors in IMU attitude and range from the scanner, there was a calculation of the resultant vertical displacement in meters of a point on a plane perpendicular to the lidar beam given a roll error between 0 and $0.1 \mathrm{deg}$ at distances up to $500 \mathrm{~m}$ from the scanner (Figure 9). For example, roll errors of 0.02 deg would result in a vertical offset in the data that ranges from near o close to the scanner, up to $0.17 \mathrm{~m}$ at $500 \mathrm{~m}$ from the scanner. Similarly, a yaw error of 0.035 deg would result in a horizontal translation of a data point by $0.2 \mathrm{~m}$ at $500 \mathrm{~m}$ from the scanner.

Figure 9. Vertical error (colors and contours) as a function of range (meters) from the scanner and estimated roll error (degrees).

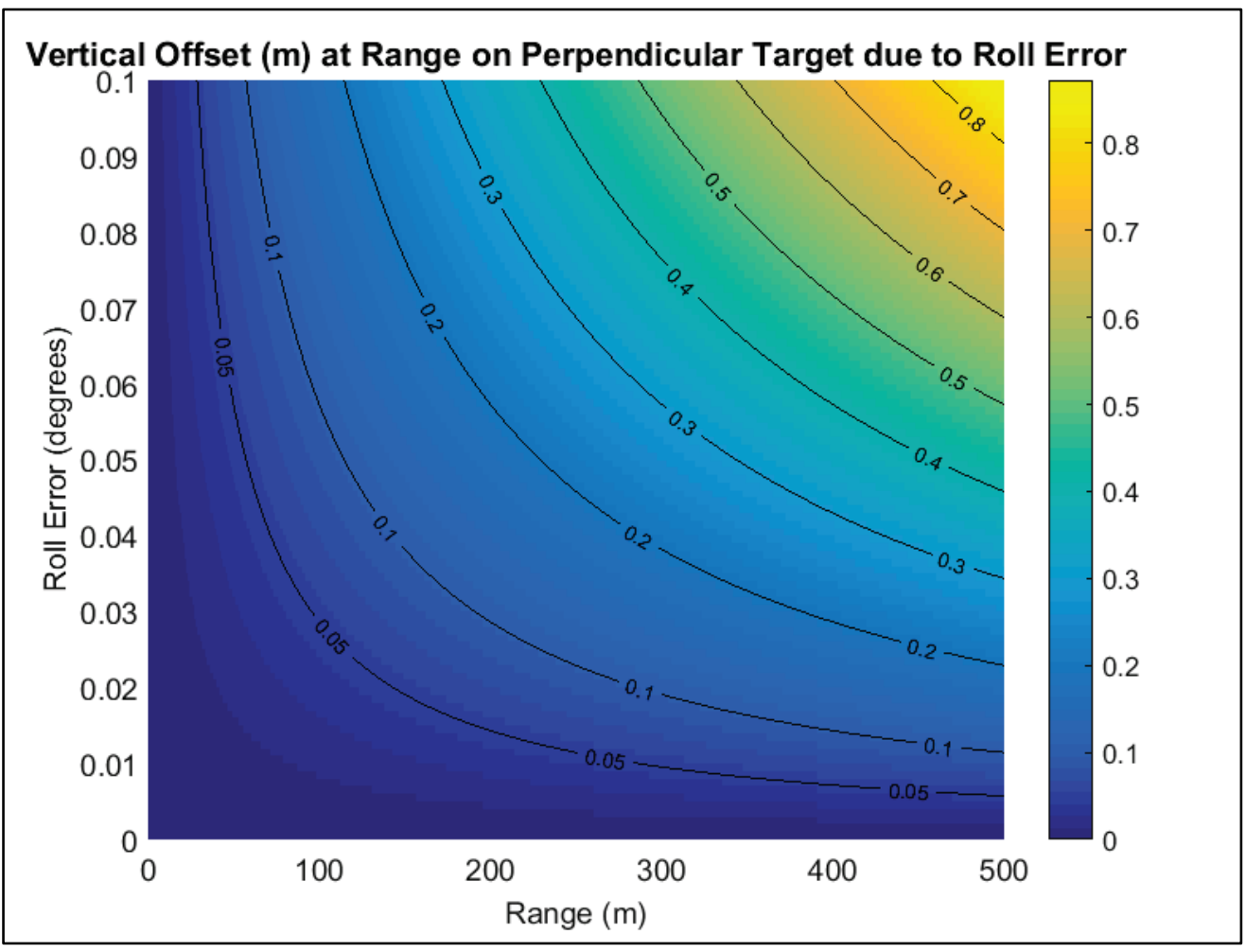


Using ten surveys of the beach in Duck, NC, there was a tabulation of estimated errors in IMU attitude and position from the Kalman-filtered SBET files. Table 2 presents the estimated RMSE for each position and orientation parameter of the smoothed best estimate of vehicle trajectory for each of the ten surveys, and also the average RMSE error for the set of surveys.

Table 2. Summary of position (easting $=x$, northing $=y$, elevation $=z$ ) and orientation RMS error over 10 surveys conducted from 2013 to 2015.

\begin{tabular}{|l|l|l|l|l|l|l|}
\hline Survey & $\begin{array}{l}\text { Northing } \\
(\mathrm{m})\end{array}$ & Easting $(\mathrm{m})$ & $\begin{array}{l}\text { Elevation } \\
(\mathrm{m})\end{array}$ & $\begin{array}{l}\text { Roll } \\
(\mathrm{deg})\end{array}$ & $\begin{array}{l}\text { Pitch } \\
(\mathrm{deg})\end{array}$ & $\begin{array}{l}\text { Heading } \\
(\mathrm{deg})\end{array}$ \\
\hline 2013 Sep & 0.010 & 0.010 & 0.019 & 0.018 & 0.018 & 0.039 \\
\hline 2013 Dec & 0.011 & 0.010 & 0.019 & 0.019 & 0.019 & 0.037 \\
\hline 2014 Feb & 0.011 & 0.011 & 0.021 & 0.020 & 0.021 & 0.036 \\
\hline 2015 Apr & 0.011 & 0.010 & 0.019 & 0.019 & 0.018 & 0.038 \\
\hline 2014 Sep & 0.011 & 0.011 & 0.020 & 0.017 & 0.018 & 0.036 \\
\hline 2014 Dec & 0.012 & 0.011 & 0.026 & 0.020 & 0.020 & 0.037 \\
\hline 2015 Feb & 0.012 & 0.011 & 0.019 & 0.020 & 0.021 & 0.043 \\
\hline 2015 Apr & 0.010 & 0.010 & 0.018 & 0.017 & 0.017 & 0.038 \\
\hline 2015 Jun & 0.011 & 0.010 & 0.016 & 0.019 & 0.020 & 0.036 \\
\hline 2015 Oct & 0.012 & 0.010 & 0.020 & 0.016 & 0.016 & 0.039 \\
\hline $\begin{array}{l}\text { Average } \\
\text { (RMSE) }\end{array}$ & 0.011 & 0.010 & 0.020 & 0.019 & 0.019 & 0.038 \\
\hline
\end{tabular}

On average, RMSE for estimated position and roll/pitch are less than the manufacturer specifications; however, they are larger for heading. The Kalman filter estimated RMSE in roll would equate to a vertical offset of $0.17 \mathrm{~m}$ at $500 \mathrm{~m}$ from the scanner. However, the distance between the foredune and the water line for most of the beaches frequently surveyed is often less than $100 \mathrm{~m}$, which would equate to a vertical offset of only $0.04 \mathrm{~cm}$. Note that the manufacturer specifications of the new GNSS would improve the accuracy on the IMU attitude to 0.005 deg in roll, which would reduce the vertical offset at $500 \mathrm{~m}$ to $0.04 \mathrm{~m}$.

\subsection{Absolute accuracy}

Absolute accuracy is the accumulation of the previously described sources of error. Control monuments and previously validated datasets are used for comparison to determine the absolute accuracy of a particular survey. This includes vetted aerial or terrestrial lidar surveys or single point measurements collected with high-precision (Trimble 2014) RTK-GPS surveying instruments (Fowler and Kadatskiy 2011). To assess the absolute 
accuracy of the system, 20 control locations (e.g., fixed corners of houses and walkways) throughout a $20 \mathrm{~km}$ stretch of coastline near Duck, NC, spaced approximately every $1 \mathrm{~km}$ were surveyed with RTK-GPS. Surveyed control points had an average horizontal residual of $0.012 \mathrm{~cm}$ and vertical residual of $0.014 \mathrm{~cm}$. These control points were used to assess any spatial trends in accuracy along the $20 \mathrm{~km}$ survey site. The base station that provided the corrections was centered in the middle of the survey site. Lidar-derived coordinates of each control point were extracted from ten surveys from 2013 to 2015 resulting in 200 observations of horizontal, vertical, and total error. The absolute position of the control points within the survey can sometimes be difficult to precisely identify in the point cloud due to the angular resolution and scan rate of the scanner. This may introduce additional errors, in some instances, on the order of several centimeters due to the user picking the "closest" measured point. The distance measured from each control point to the position in the point cloud was measured as absolute distance and for each location. Figures 10 and 11 show the mean horizontal and vertical error at each control location and Figure 12 shows the combined total error as a function of distance from the base station.

Figure 10. Average horizontal error at each control point location for 10 surveys along a $20 \mathrm{~km}$ stretch of coastline.

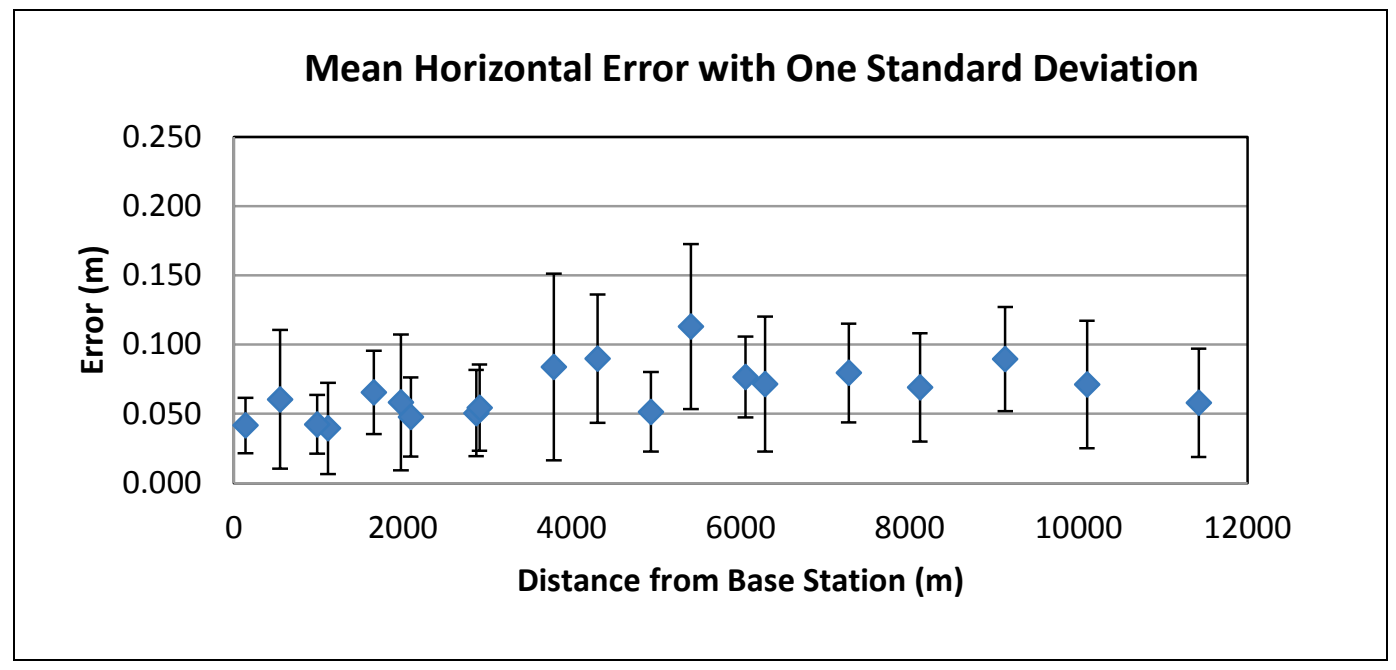


Figure 11. Average vertical error at each control point location for 10 surveys along a $20 \mathrm{~km}$ stretch of coastline.

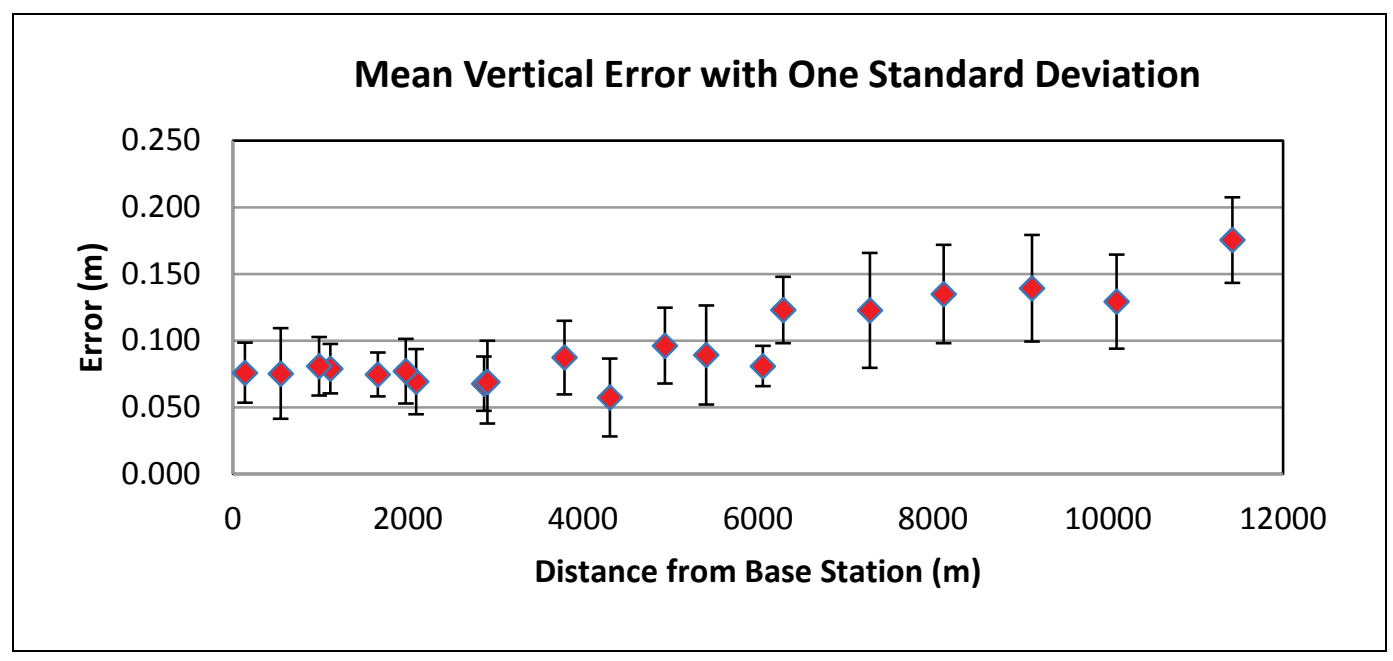

Figure 12. Average total error at each control point location for 10 surveys along a $20 \mathrm{~km}$ stretch of coastline.

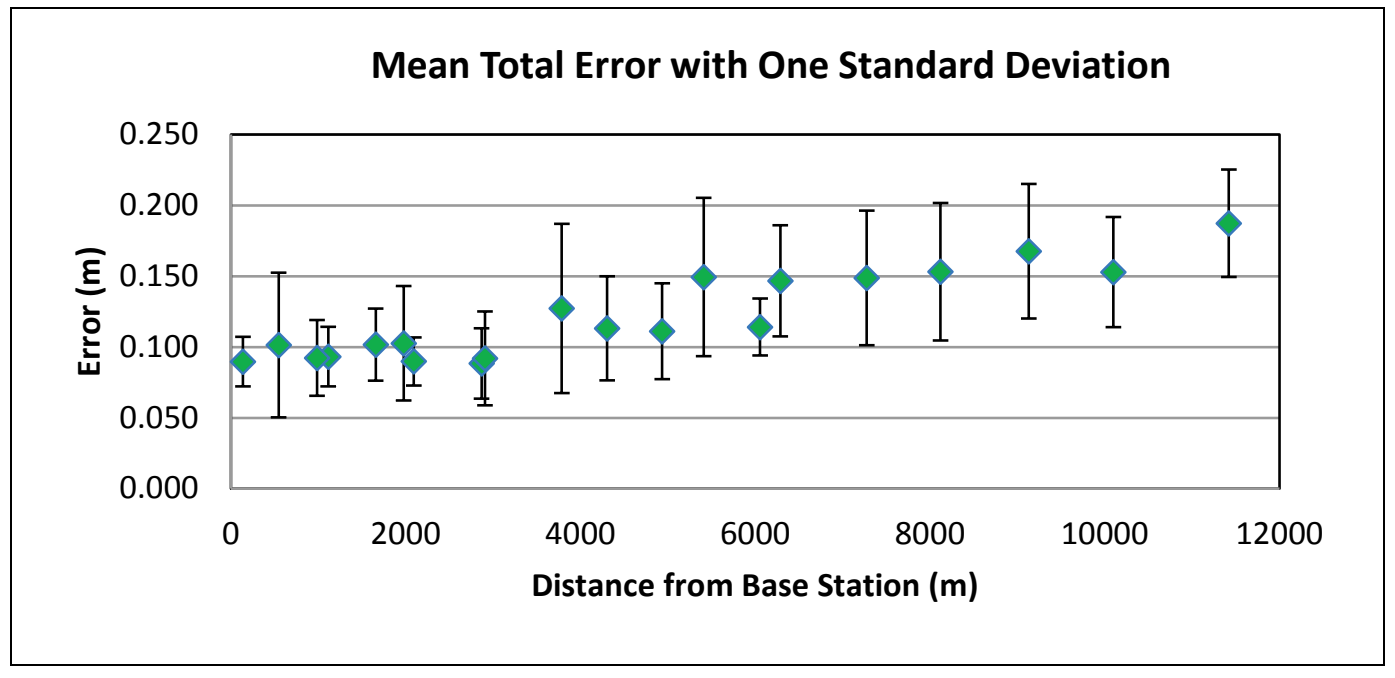

Horizontal error showed no trends in distance from base station; however, vertical error began to increase from $0.1 \mathrm{~m}$ at $6000 \mathrm{~m}$ from the base station up to $0.17 \mathrm{~m}$ at $12000 \mathrm{~m}$ from the base station. Total error was dominated by the vertical error component and showed a similar trend in increasing error with distance from the base station. This spatial pattern is consistent with previous work noting the degradation of GPS corrections with distance from the base station (Raquet 1998) and may indicate that GPS translation errors are a significant source of error in the system. 
Table 3 summarizes the average expected system error from the ten analyzed surveys.

Table 3. Absolute errors of the system from 20 spatially distributed control locations over 10 separate surveys.

\begin{tabular}{|l|l|l|l|}
\hline & Horizontal & Vertical & Total \\
\hline RMS Error $(\mathrm{m})$ & 0.075 & 0.099 & 0.126 \\
\hline
\end{tabular}

To put these values in context with the error from other methods of beach surveying, Sallenger et al. (2003) includes GPS mounted to an all-terrain vehicle for kinematic surveys, GPS mounted to a stadia rod for static or kinematic point surveys, and airborne lidar. The GPS surveys' accuracy is a function of the hardware and correction data used to obtain the solution. The accuracy of the current GPS hardware is approximately $0.015 \mathrm{~m}$ horizontally and $0.02 \mathrm{~m}$ vertically. Sallenger et al. report $0.15 \mathrm{~m} \mathrm{RMS}$ error for the airborne lidar beach surveys when compared to the values obtained by GPS.

\subsection{Repeatability}

To quantify the repeatability of the survey, the position and shape of static structures within the survey are extracted from each of the ten datasets. The point spread from the ten surveys is measured on hard vertical structures such as building walls. Vertical structures are used to negate effects from scanner beam divergence, as the target is roughly perpendicular to the lidar scanner and is least affected by position errors. Narrow transects ( $5 \mathrm{~cm}$ wide) are sliced through the point clouds in each of the ten surveys, and the point spread across this transect is measured to quantify the "thickness" of the vertical structure as observed over ten surveys. The ten surveys were sampled at 20 locations and resulted in an average of $0.05 \mathrm{~m}$ precision with a standard deviation of $0.02 \mathrm{~m}$. Figure 13 shows the spatial variability of the point spread with respect to the distance from the base station. Repeatability showed no trends with distance from the base station and ranged from $0.02 \mathrm{~m}$ to $0.06 \mathrm{~m}$ along the survey region. 
Figure 13. The average precision of the system is $0.05 \mathrm{~m}$.

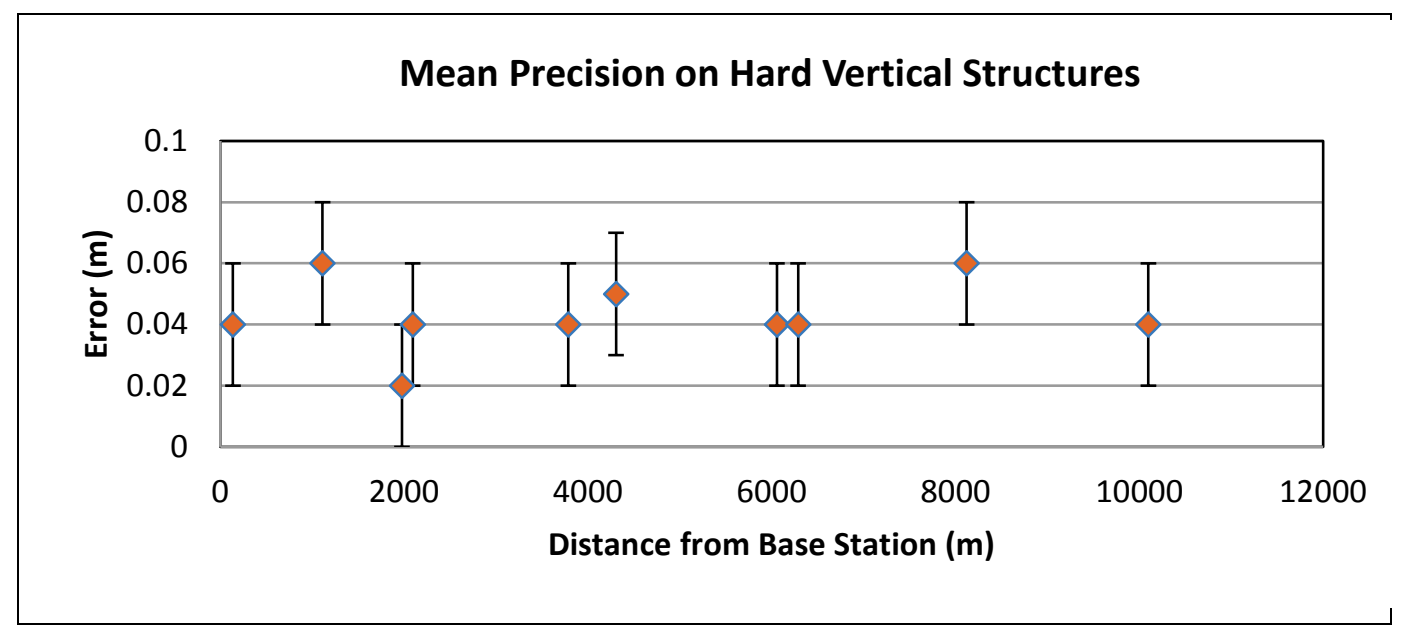

\subsection{Total propagated error}

Future work will focus on implementing total propagated error (TPE) for each lidar point using an approach similar to Glennie (2007). This will account for spatial and temporal variability in the errors introduced by the trajectory (IMU attitude and GPS position) and scanner angle measurements (relative geometry between the beam divergence and the terrain slope). TPE will generate an error ellipse for each point in the point cloud, which will provide a quantitative estimate of its error. This should yield more robust error estimates that correctly reflect the variable quality of the data and allow for more accurate calculation of beach volume change and the associated errors. A drawback of the TPE approach will be an increase in the data storage requirements, as each individual scan point will now include additional error information. 


\section{Data Products}

\subsection{Classified .las point cloud}

After processing accuracy analysis and QA/QC is complete, the resulting point cloud is filtered to segregate ground, non-ground, and water points. First, the shoreline is manually digitized at the location where returns from the water and returns from the wetted sand meet. All points that reside offshore of this line are classified as water. A proprietary terrain filter within Riegl's RiProcess software is utilized for the filtering process of the terrestrial points. The filter works in a hierarchical manner, assessing the distances of points from an estimated ground surface, in which a coarser-to-finer grid is applied to the data based on the input parameters noted below:

- Base grid size $(\mathrm{m})$ - corresponds to the edge length of the finest grid cell size

- Number of levels (n) - defines the number of levels used in the process; the coarsest grid cell size is the product of the base grid size and $2^{(\mathrm{n}-1)}$

- Tolerance factor - specifies the cutoff planes for the data to be classified as ground or non-ground at each level

- Percentile (\%) - determines the percentage of points within a cell that are below the representative cell point, used to define the cell's representative local surface

- Maximum slope angle (deg) - specifies the maximum angle to which the filter is applied

- Second filter step - useful for performing a second, more aggressive filter to remove artifacts not caught by a single tolerance factor

- Tolerance factor \#2 - same as above but only applied when using a second filter step (typically lower than initial tolerance factor)

- Buffer zone width (m) - only used if second filter step is applied and specifies the number of base grid cells that the morphological filter uses

- Fine filter tolerance value - similar to above tolerance factor and specifies the maximum distance from the defined planes for fine filtering 
The filtering operation is memory intensive and is completed on multiple subsets of the surveyed region. Once the operation is complete, non-ground points are selected and are marked as "unclassified" points due to the mixture of vegetation, sand fencing, dune walkways, and structures within the selected points. The remaining points are classified as ground and will be used to generate elevation models. The point cloud is exported as a single .las file or multiple .laz files and can be viewed in a variety of commercial or open source software packages.

\subsection{Digital elevation model (DEM) generation}

Digital elevation models (DEMs) are derived from the ground-classified points within filtered and classified point clouds. Points are typically gridded at $0.5 \mathrm{~m}$ resolution using the Points2Grid algorithm developed by the OpenTopography point cloud processing system. OpenTopography is actively developed by the U.S. Army Engineer Research and Development Center, Cold Regions Research Laboratory, and an example of the Points2Grid algorithm gridding routine is shown in Figure 14. The user defines the grid resolution and search radius (Kim et al. 2006), and the algorithm computes interpolated elevation values.

Figure 14. Points2Grid algorithm neighborhood search from opentopography.org; black dots represent lidar point data, red circles denote the bin size (i.e., search radius) for the DEM grid node; and the black crosses indicate the elevation estimate for the grid node (from OpenTopography 2016).

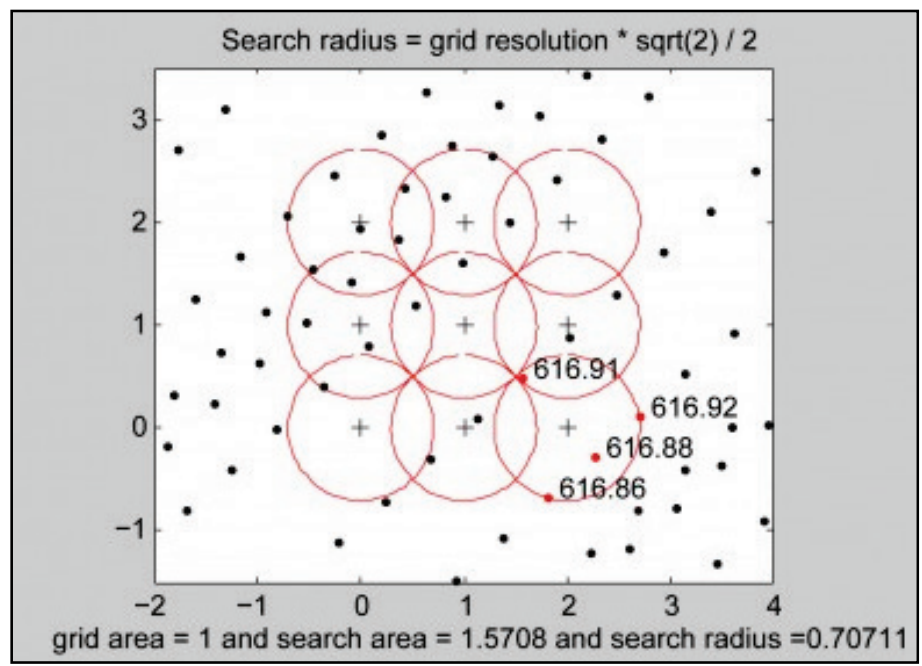

The dense lidar point cloud data is gridded at $0.5 \mathrm{~m}$ resolution to preserve the detail in the morphology and represent the surface on an evenly spaced grid. However, interpolating the data at a coarser resolution than the 
original point density will misrepresent some of the features. Tests of various cell sizes were conducted with the data, and the $0.5 \mathrm{~m}$ size provides a balance between file size and minimizing the error introduced by interpolation. Figure 15 is a transect view illustrating the effect of grid interpolation on the bare earth morphology. Note how the grid cell size limits how the steep regions are represented due to large vertical changes occurring over intervals smaller than the cell size.

Figure 15. Cross-shore transects of the ground lidar points and the generated DEM surface showing good agreement (top panel) and poor agreement (bottom panel) between the original data and the final DEM.

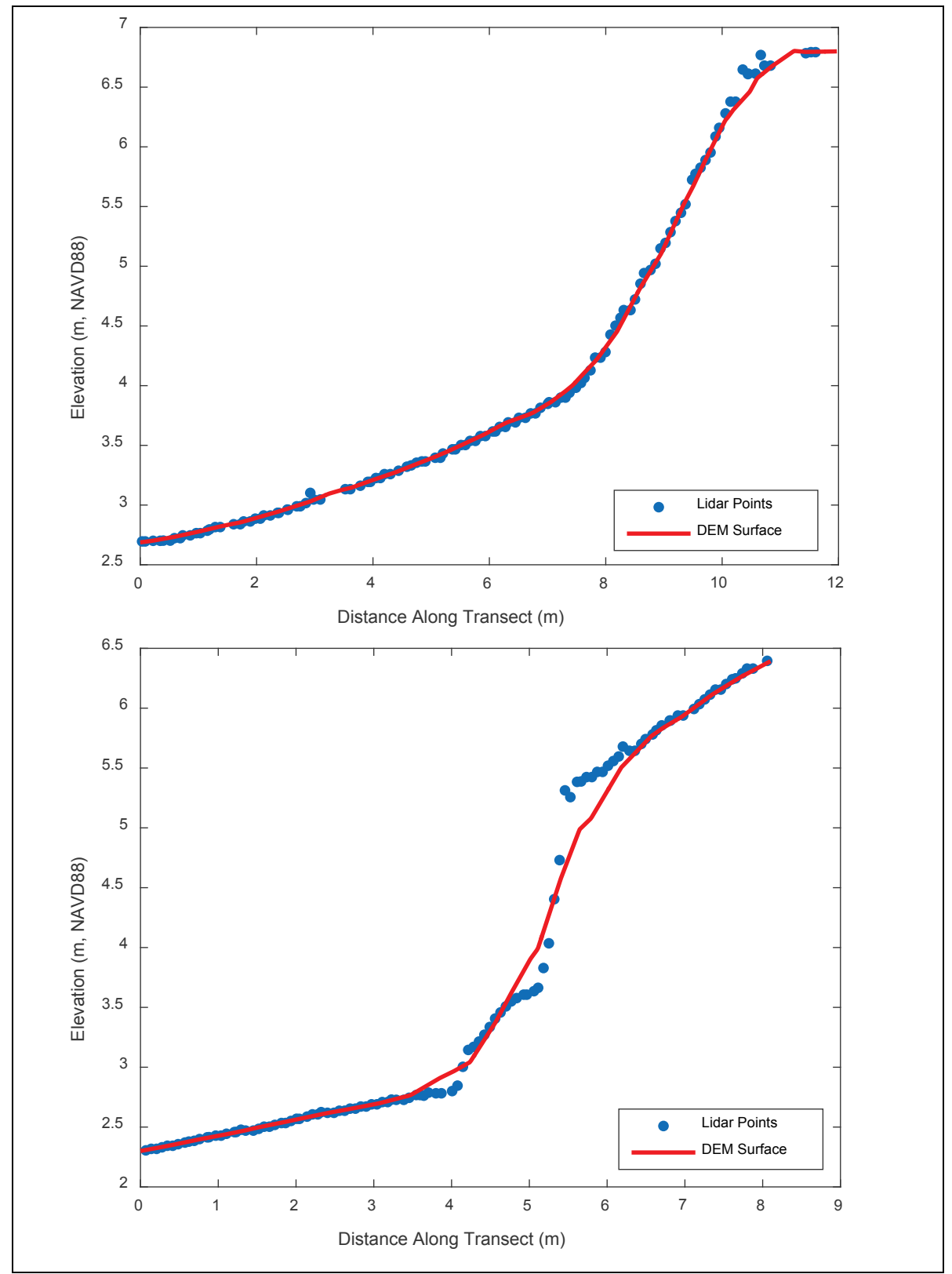




\subsection{Example products}

The resulting classified point clouds and DEMs can be used in a variety of ways to assess the influence of coastal processes on the surrounding morphology. Some examples include elevation change maps (Figure 16), where two surveys that are measured at different times but overlap spatially. The elevation values are subtracted between the two dates, resulting in a change map. These maps can be used to quantify spatial variation in beach morphological evolution and volume change. For example, the user could utilize these maps to assess where wave runup impacted the foreshore, upper beach, and dune toe, as well as areas where aeolian transport has deposited sediment along the foredune. Figure 16 also shows two alongshore and cross-shore transects that illustrate the elevation changes over a 3-month period.

Figure 16. Elevation change map results from subtracting two surveys that occur at different times (t1 = Jan 2016; $\mathrm{t} 2$ = Apr 2016) but overlap spatially. Cool colors indicate areas of accretion, and warm colors indicate areas of erosion. Example transect plots from A-A' and B-B' are shown in the lower right.

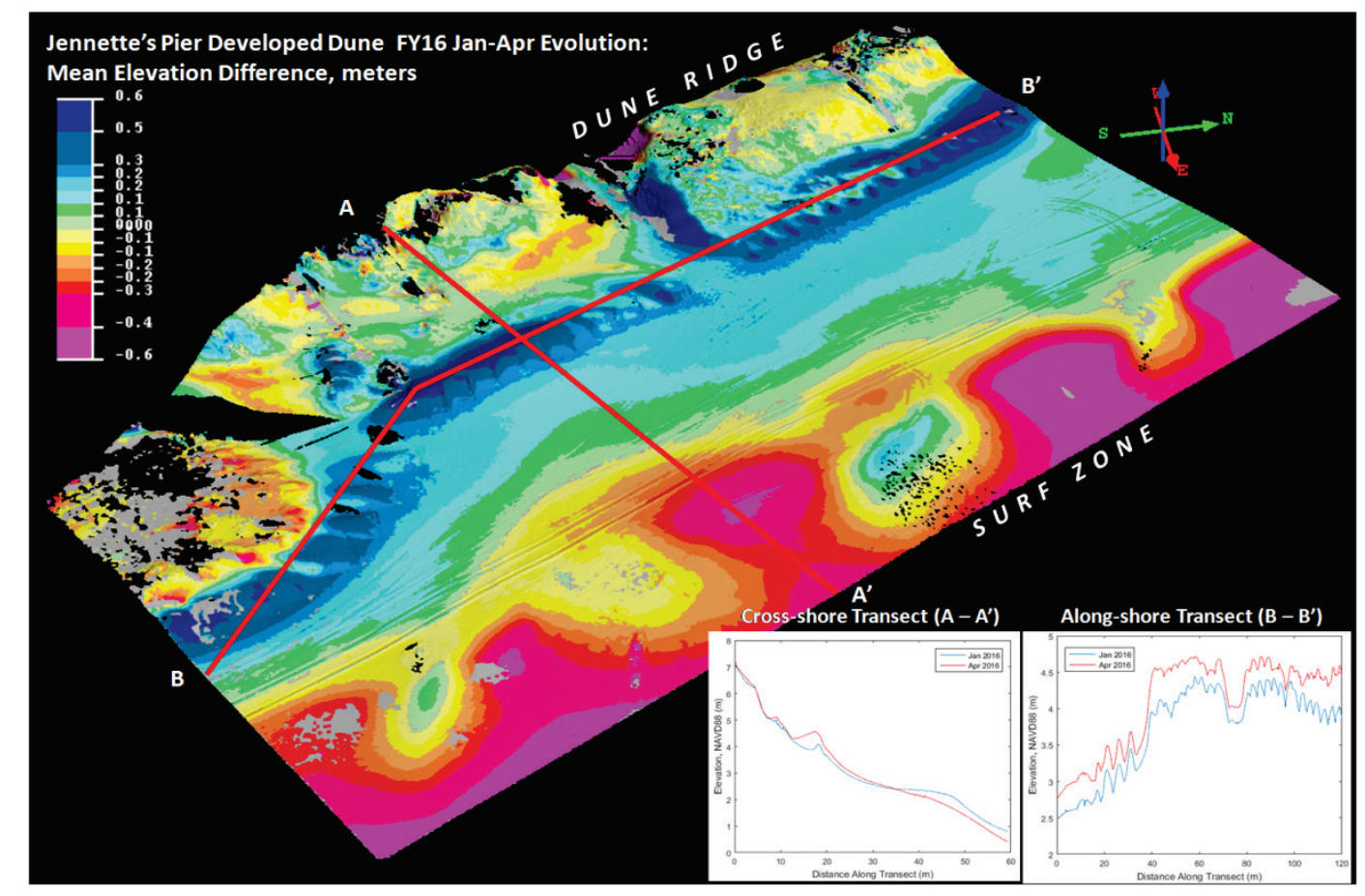

Contour information, particularly shoreline position, can also be extracted from the resulting point clouds or DEMs as seen in Figure 17. The high-resolution products allow for seamless and accurate contour generation for the entire survey extent due to the extensive coverage of the lidar data. These techniques can be expanded to calculate beach/berm widths, slopes, and dune toe and dune crest positions. 
Figure 17. 1 me, NAVD88 contour generation for five surveys overlaid on the most recent point cloud (May 16). Solid lines denote $1 \mathrm{~m}$ elevation contours from five surveys conducted between November 2015 and May 2016.

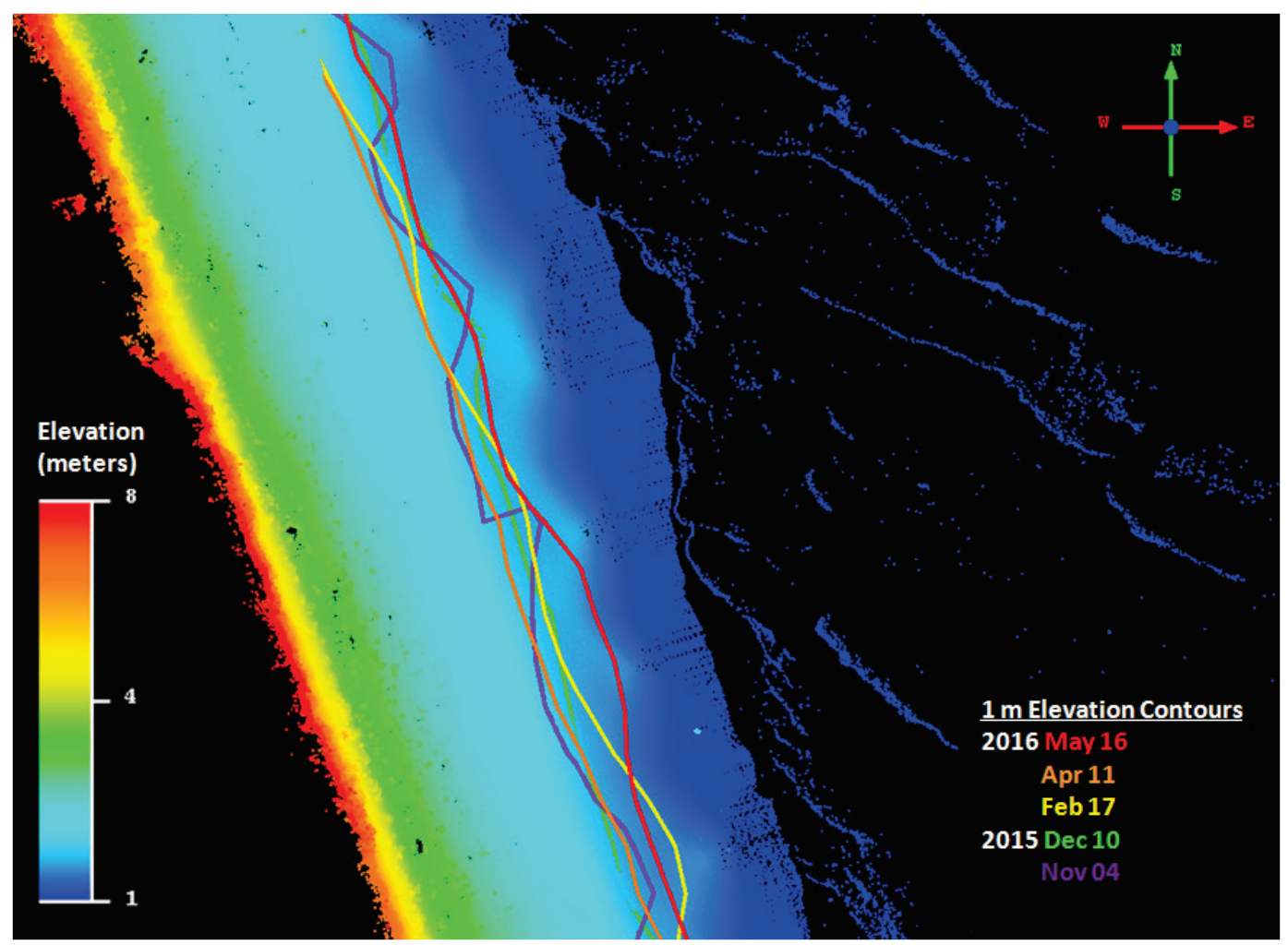

Automated algorithms have also been developed to assess the various morphological parameters of the foredune from terrestrial lidar based DEMs (Brodie and Spore 2015). Figure 18 show an example of an automated dune state classification product based on the dune toe and dune crest elevations, dune slope, volume, and curvature from the terrestrial lidar data. The algorithm ingests the physical parameters, calculates the derived parameters, and outputs a rating scale for every 50 $\mathrm{cm}$ transect along the survey extent. The rating scale relates the foredune geometry with current state or health of the foredune (healthy/mature, recovering, scarped, man-made) and provides an alongshore spatial map as seen in the right of Figure 18. 
Figure 18. Dune state classification based on the geometry of the foredune, measured by the mobile, terrestrial scanner. Physical and calculated parameters of the foredune geometry are shown in the vertical bars on the left, and the resulting classification is shown on the right (from Brodie and Spore 2015).

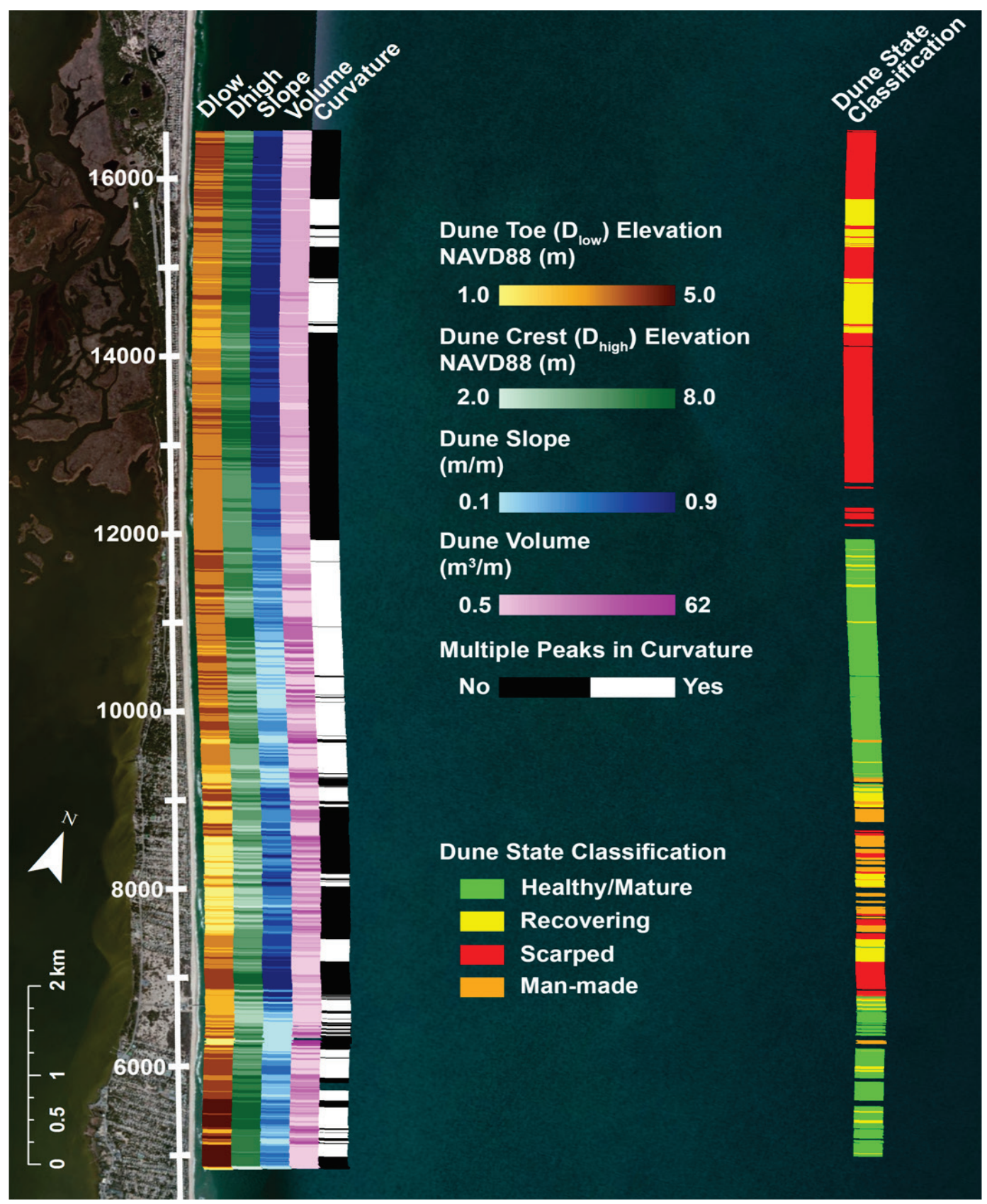




\section{Conclusion}

The CLARIS mobile, terrestrial lidar system has been described, to include the various system components, data acquisition, processing, and QA/QC procedures. The calculated accuracy of the system showed a horizontal RMS error of $0.075 \mathrm{~m}$, vertical RMS error of $0.099 \mathrm{~m}$, and total error of $0.129 \mathrm{~m}$ and an average repeatability of $0.05 \mathrm{~m}$. Due to the dynamic quality of the GPS/IMU data of the navigation system, assigning a blanket accuracy value to an entire mobile survey will require detailed error propagation for all system components as outlined by Glennie (2007). This will provide a more rigorous error report, potentially assigning an error ellipse around each point within the resulting point cloud. 


\section{References}

Applanix. 2015. POS LV specifications.

http://www.applanix.com/media/downloads/products/specs/poslv_specificatio ns12032012.pdf.

Barber, D. M., and J. P. Mills. 2007. Vehicle based waveform laser scanning in a coastal environment. In Proceedings of the 5th International Symposium on Mobile Mapping Technology, Padua, Italy, May 29-31, 2007.

Barber, D., J. Mills, and S. Smith-Voysey. 2008. Geometric validation of a ground-based mobile laser scanning system. ISPRS Journal of Photogrammetry and Remote Sensing 63(1), 128-141.

Bitenc, M., R. Lindenbergh, K. Khoshelham, and A. P. Van Waarden. 2011. Evaluation of a LiDAR land-based mobile mapping system for monitoring sandy coasts.

Remote Sensing 3(7):1472-1491.

Brodie, K. L., and N. J. Spore. 2015. Foredune classification and storm response: automated analysis of terrestrial lidar DEMs. In The Proceedings of the Coastal Sediments 2015 .

Fowler, A., and V. Kadatskiy. 2011. Accuracy and error assessment of terrestrial, mobile and airborne lidar. In Proceedings of American Society of Photogrammetry and Remote Sensing Conference (ASPRS 2011), Milwaukee, WI, USA, May 1-5, 2011.

France, J. I., and W. Butler. 2012. Mobile system angular alignment quality analysis. In Proceedings of American Society of Photogrammetry and Remote Sensing Conference (ASPRS 2012), Sacramento, CA, USA (Vol. 16).

Glennie, C. 2007. Rigorous 3D error analysis of kinematic scanning LIDAR systems. Journal of Applied Geodesy 1(3):47-157.

Haala, N., M. Peter, J. Kremer, and G. Hunter. 2008. Mobile LiDAR mapping for 3D point cloud collection in urban areas-A performance test. The International Archives of the Photogrammetry, Remote Sensing and Spatial Information Sciences 37:1119-1127.

IXBlue. 2016. ATLANS-C mobile mapping position and orientation solution. https://www.ixblue.com/sites/default/files/downloads/ixblue-br-atlans-c-o82014-web 0.pdf.

Kim, H., J. Arrowsmith, C. J. Crosby, E. Jaeger-Frank, V. Nandigam, A. Memon, and C. Baru. 2006. An efficient implementation of a local binning algorithm for digital elevation model generation of LiDAR/ALSM dataset. In AGU Fall Meeting Abstracts. Vol. 1, p. 0921.

Lim, S., C. A. Thatcher, J. C. Brock, D. R. Kimbrow, J. J. Danielson, and B. J. Reynolds. 2013. Accuracy assessment of a mobile terrestrial lidar survey at Padre Island National Seashore. International Journal of Remote Sensing 34(18):6355-6366. 
OpenTopography. 2016. Points2Grid: A local gridding method for DEM generation from lidar point cloud data. www.opentopography.org/otsoftware/points2grid

Raquet, J. F. 1998. Development of a method for kinematic GPS carrier-phase ambiguity resolution using multiple reference receivers. No. AFIT-FY99-62. Wright Patterson Air Force Base: Air Force Institute of Technology.

Rieger, P., N. Studnicka, M. Pfennigbauer, and G. Zach. 2010. Boresight alignment method for mobile laser scanning systems. Journal of Applied Geodesy 4(1):13-21.

Riegl Laser Measurment Systems GmbH. 2015. Riegl VZ-10oo Datasheet. http://www.riegl.com/uploads/tx pxpriegldownloads/DataSheet VZ-

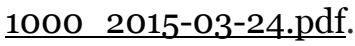

Riegl Laser Measurment Systems GmbH. 2015. Riegl VZ-200o Datasheet. http://www.riegl.com/uploads/tx pxpriegldownloads/DataSheet VZ2000 2015-03-24.pdf.

Sallenger, Jr., A. H., W. B. Krabill, R. N. Swift, J. Brock, J. List, M. Hansen, R. A. Holman, S. Manizade, J. Sontag, A. Meredith, and K. Morgan. 2003. Evaluation of airborne topographic lidar for quantifying beach changes. Journal of Coastal Research 19(1):125-133.

Toth, C. K. 2009. In Proceeding of ASPRS 2009 Annual Conference, Baltimore, Maryland, March 9-13, 2009, 1-7.

Trimble Navigation Limited. (2014). Trimble R10 GNSS system datasheet. http://trl.trimble.com/docushare/dsweb/Get/Document-625158/022543544E TrimbleR10_DS 1014_LR.pdf. 


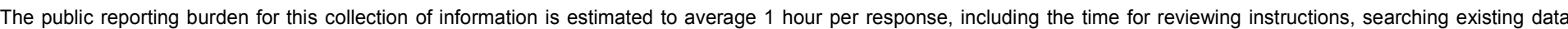

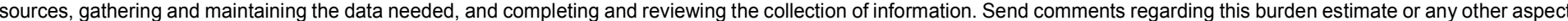

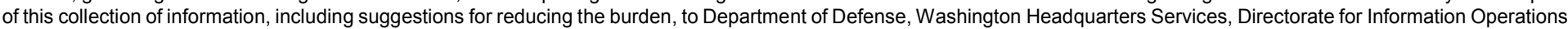

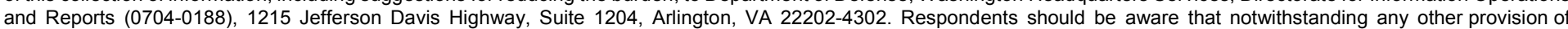
law, no person shall be subject to any penalty for failing to comply with a collection of information if it does not display a currently valid OMB control number. PLEASE DO NOT RETURN YOUR FORM TO THE ABOVE ADDRESS.

\begin{tabular}{l|l|c}
\hline $\begin{array}{l}\text { 1. REPORT DATE } \\
\text { April } 2017\end{array}$ & 2. REPORT TYPE & 3. DATES COVERED (From - To) \\
& Final Report &
\end{tabular}

\section{TITLE AND SUBTITLE}

5a. CONTRACT NUMBER

Collection, Processing and Accuracy of Mobile Terrestrial Lidar Survey Data in the

Coastal Environment

5b. GRANT NUMBER

5c. PROGRAM ELEMENT NUMBER

6. AUTHOR(S)

Nicholas J. Spore, Katherine L. Brodie

\section{5d. PROJECT NUMBER}

5e. TASK NUMBER

5f. WORK UNIT NUMBER

H70H6B

8. PERFORMING ORGANIZATION REPORT NUMBER

ERDC/CHL TR-17-5

U.S. Army Engineer Research and Development Center

1261 Duck Road

Kitty Hawk, NC 27949

9. SPONSORING/MONITORING AGENCY NAME(S) AND ADDRESS(ES)

U.S. Army Corps of Engineers

Washington, DC 20314-1000
10. SPONSOR/MONITOR'S ACRONYM(S)

HQUSACE

11. SPONSOR/MONITOR'S REPORT NUMBER(S)

\section{DISTRIBUTION/AVAILABILITY STATEMENT}

Approved for public release; distribution is unlimited.

\section{SUPPLEMENTARY NOTES}

\section{ABSTRACT}

The purpose of this Coastal and Hydraulics Engineering technical report is to present how elevation data is collected along the coast using terrestrial lidar scanners coupled with a global position system/inertial navigation system and assess the accuracy of the data. A brief overview of the technology utilized on the vehicle platform is presented, along with upcoming improvements. This is followed by a description of the data processing techniques utilized to create three-dimensional point clouds. Subsequent to that is a presentation of an accuracy assessment to provide an overall system performance summary and provide a few examples of data products and their uses. The accuracy assessment of the system resulted in a mean horizontal error of 0.075 meter $(\mathrm{m})$, mean vertical error of $0.099 \mathrm{~m}$, mean total error of $0.129 \mathrm{~m}$, and an average repeatability of $0.05 \mathrm{~m}$. The results of this report suggest that assigning a single accuracy value to a mobile lidar survey may misrepresent some of the spatially variable error throughout the survey, and further work should incorporate full error propagation to each point.

\section{SUBJECT TERMS}

Coasts, Digital elevation models, Electronic data processing, Optical radar--Evaluation

\section{SECURITY CLASSIFICATION OF:}

\begin{tabular}{|l|c|l|l|}
\hline a. REPORT & b. ABSTRACT & c. THIS PAGE & ABSTRACT \\
Unclassified & Unclassified & Unclassified & SAR \\
\hline
\end{tabular}

18. NUMBER OF 19a. NAME OF RESPONSIBLE PERSON PAGES Nicholas J. Spore

38 19b. TELEPHONE NUMBER (Include area code) 252-261-6840 